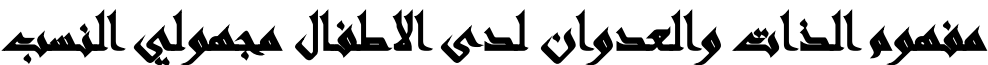

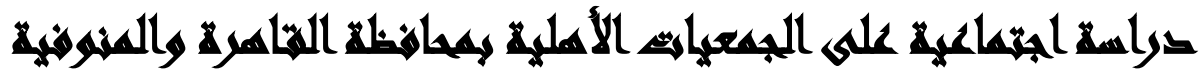

[V]

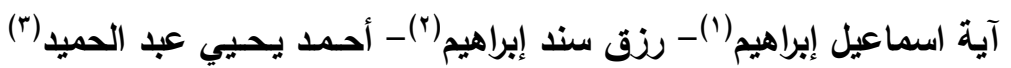

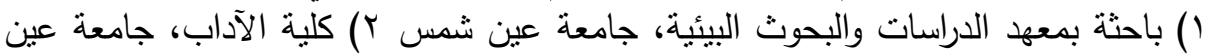

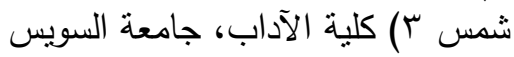

\section{المهرتيلى}

استهدفت الدراسة التعرف على أهم المشكلات النفسية والاجتماعية للاطفال مجهولي

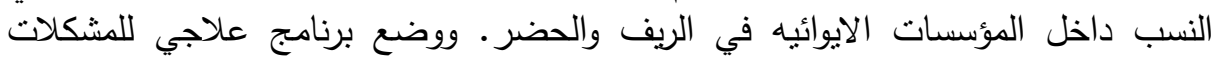
الاجنماعية والنفسية لدى الطفل مجهول النسب في المؤسسات الإيوائيه في الريف واليف والحضر.

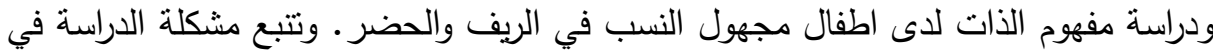
تعرض الاطفال مجهولي النسب الي المشكلات النفسية والاجتماعية التي يعانون منها الاطفال الطفال

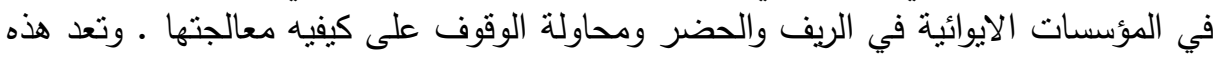

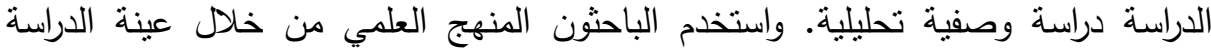

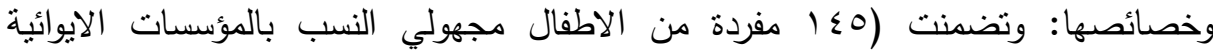

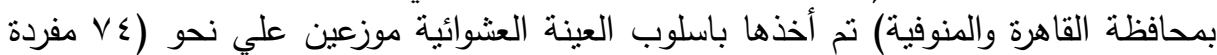

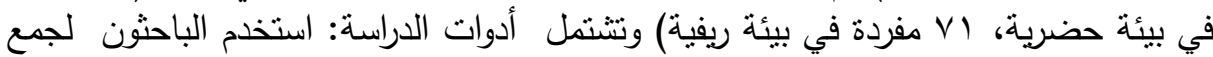

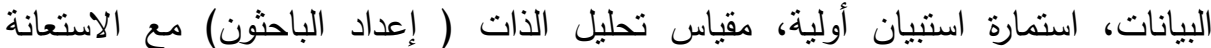
بالدراسات والبحوث السابقة.

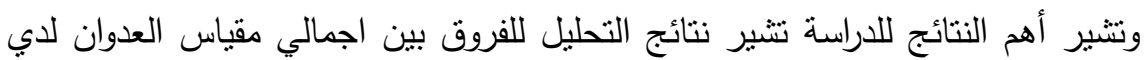

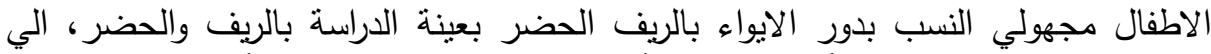

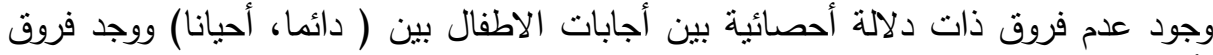

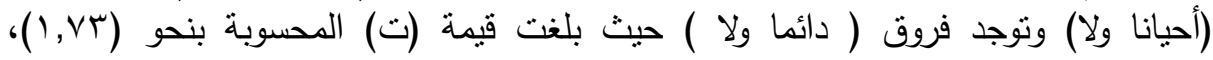

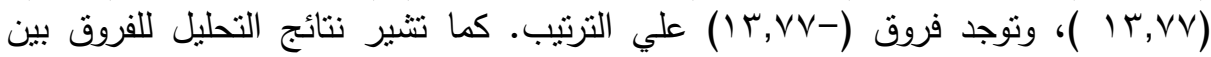

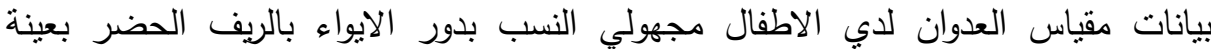

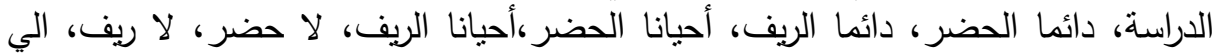

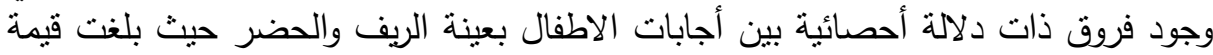

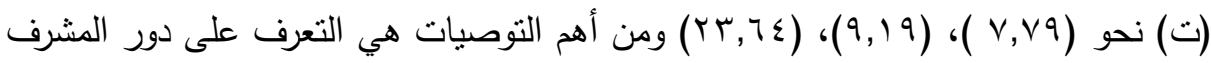




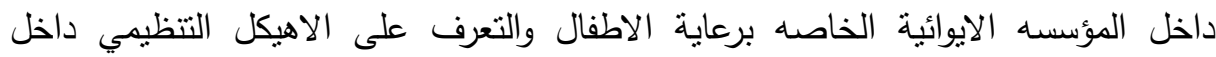

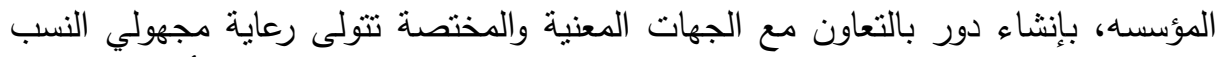

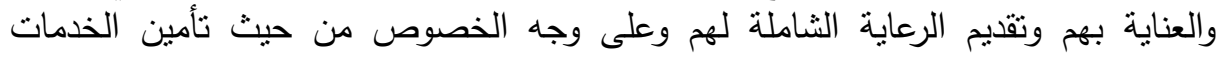

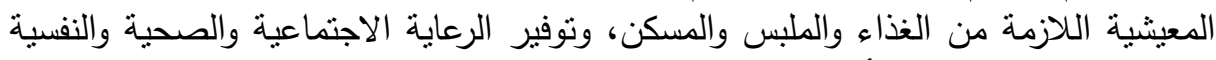

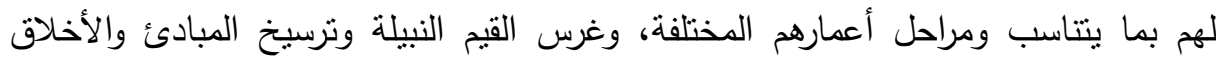

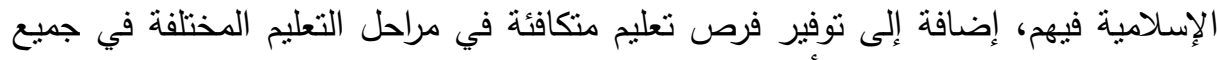

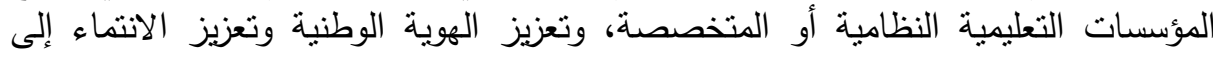

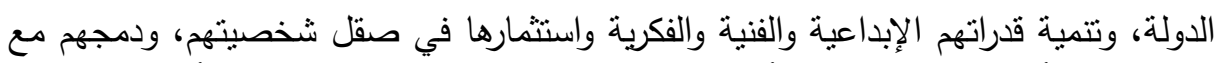
غيرهم من الأطفال في المراكز والأندية الرياضية والنقائة والفية والثية والمخيمات وتوفير الأنشطة المناسبة

\section{هin}

إن الطفل الذي يتعرض للحرمان من الوالدين يفقد كل المميزات التي يكتسبها الطفل الذي

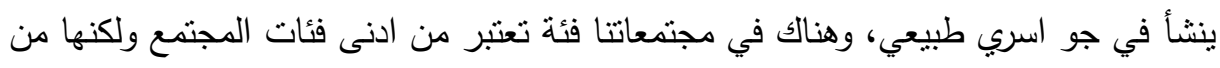

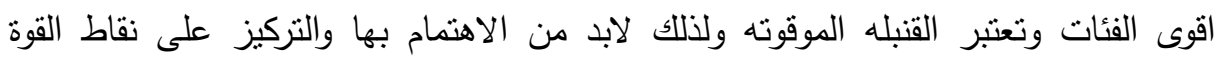
والضعف حتى لا يحدث اي مشكلات تؤثر على المجتمع بالسلب وان هذه الفئة يمكن ان تتجرف مع الجماعات الطائفيه التي تؤثر على عقول هؤلاء الاطفال الذين لا حول لهم ولا قوة.

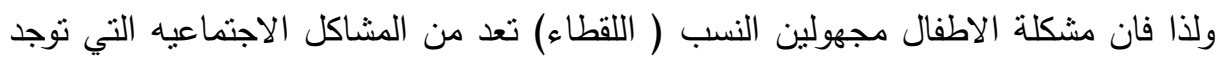

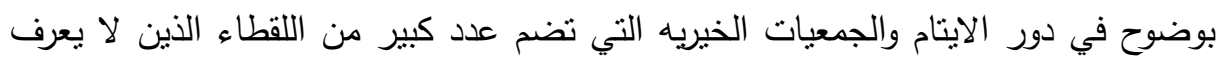

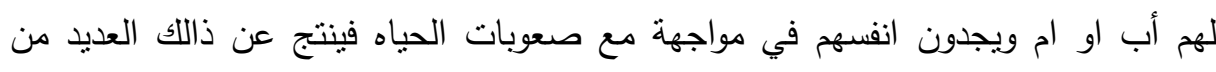

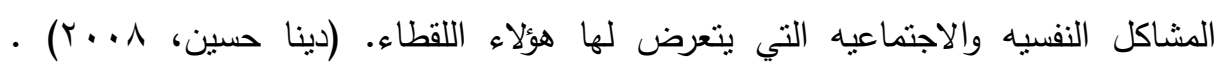
وشريحه الاطفال اللقطاء موجوده في المجتمع ولا بد من تأهيلها وتوظيفها لخدمة المجتمع ولاه

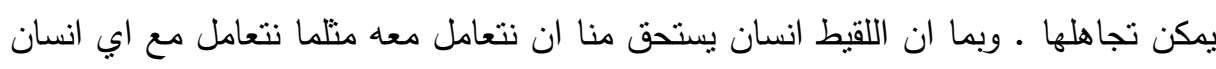

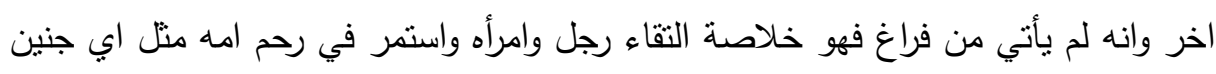

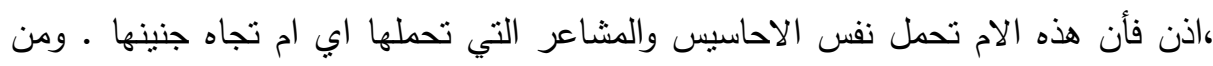
هنا ينبغي تفويض امر الايتام الى الاشخاص الذين يتمتعون بثنات في الثخصيه ،ويتعاملون

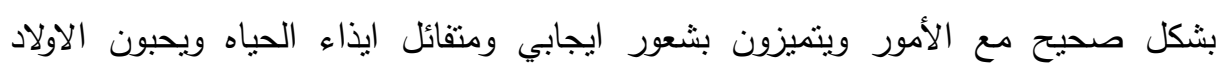


وتربيتهم والأهم من ذاللك الأمانه والرغبه الحقيقيه في ان يعيش الطفل عندهم في راحه وسلام.

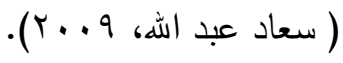
إن مفهوم الذات يمكن ان يتحدد الى درجه كبيره من خلال معرفة الفرد لوجهات نظر

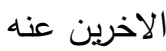

وأيا كانت الطريقه التي يلجأ اليها الفرد في تحديد ذاته فالفرد قد يرى نفسه بصوره ايجابيه احيانا وبصوره سلبيه احيانا اخرى ولذا فالاسره المترابطه التي توفر جوا امنا من الحب والرعايه والتي ترعى القيم الايجابيه وتبعد الطفل عن العادات والقيم السلبيه وتتجعه على استغلال مواهبه وقدراته وتعوده على التعاون والمشاركه في جو من المحبه والقلفه وكل هذا يكون النواه

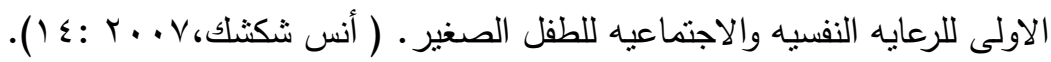

\section{مئ}

استتدت الدراسة في الوصول لتحديد مشكلة الدراسة الي نتائج الدراسات والبحوث السابقة

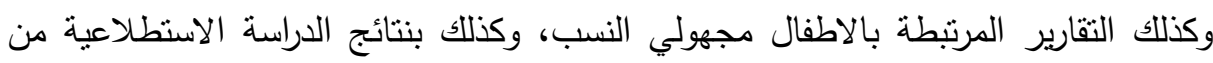
واقع خبرة عمل الباحثة. وصل عدد الأطفال مجهولي النسب في مصر إلى ب مليون طفل

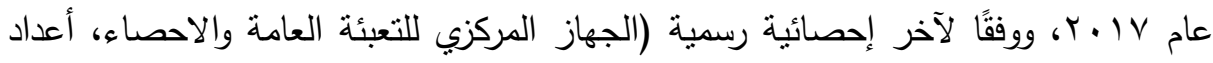
مختلفة )، ويطلق لقب (مجهول النسب) على الأطفال، الذين تم إيجادهم في صناديق القمامة بالثارع أو أمام أبواب المسجد أو على جانبي الطريق، ليلقاهم أصحاب القلوب الرحيمة.

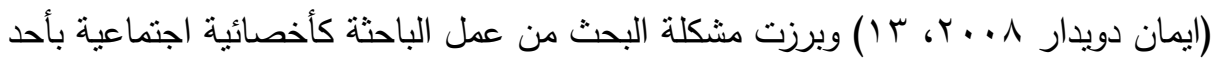
دور الرعاية الاجتماعية حيث رأت الباحثون أن الاطفال مجهولين النسب الذين ينم التقاطهر

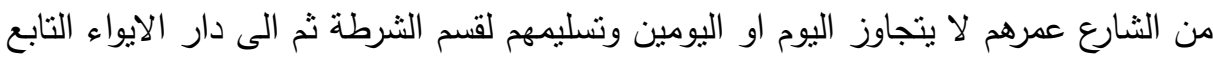

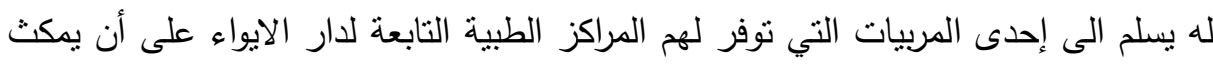
الطفل مجهول النسب لديها سنه كاملة وبعد ذللك يسلمون الى احدى المؤسسات الايوائية التابعة لوزارة التضامن الاجتماعي وتسلم بواسطتها الطفل او الطفله الى احدى الاسر البديلة

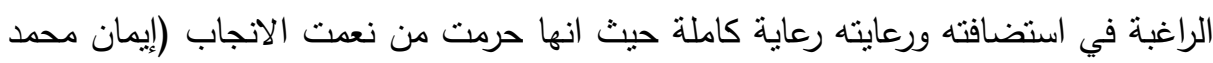

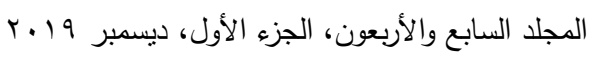


النبوى صالح، 1 . . ץ). يلتحق الطفل بالمؤسسة الايوائية نتيجه لأسباب اجتماعيه او مجتمعية

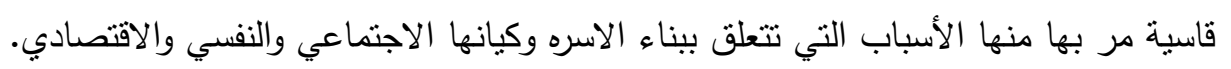

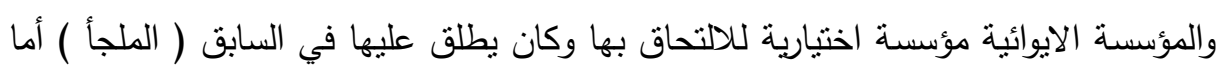
الان فبتطور الرعاية الاجتماعية أصبح يطلق عليها مؤسسة الاطفال المحرومين من الرعاية

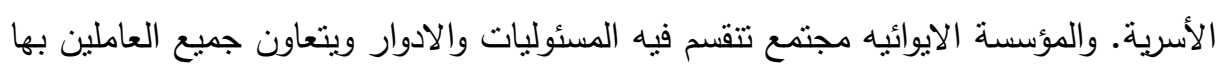
من أجل تحقيق هدف واحد الا وهي تعويض هؤلاء الاطفال المحرومين من الرعايه الاسريه

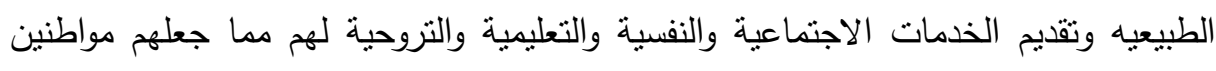

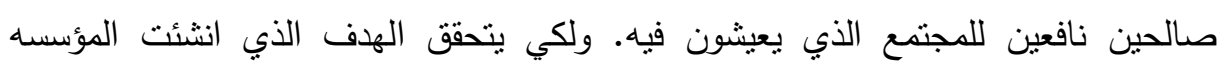

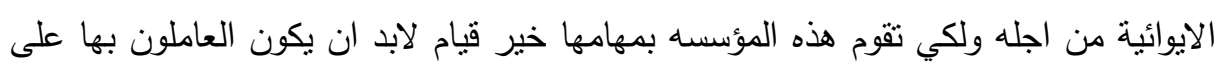

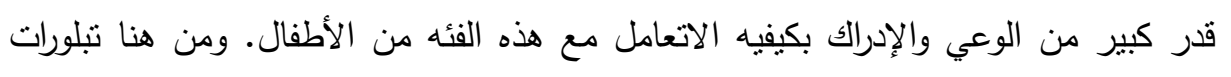

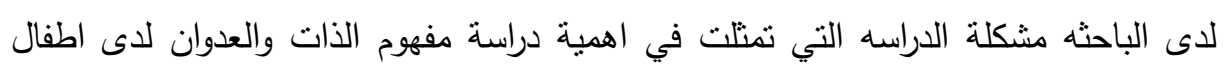

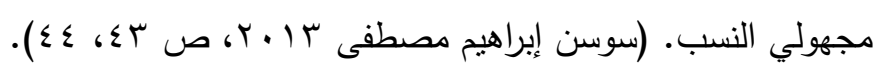

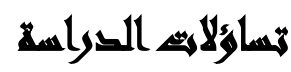

تكمن في التعرف على المشكلات النفسية والاجتماعية التي يعاني منها الأطفال مجهولي

النسب في المؤسسات الايوائية في الريف والحضر ومحاولة الوقوف على كيفيه معالجتها. تتلخص مشكلة الدراسة في الاجابة عن التساؤلات التالية:

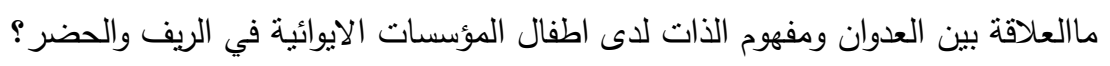

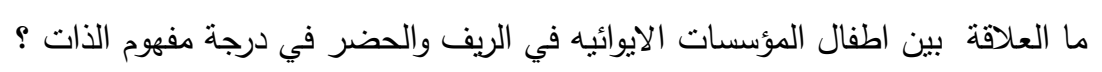

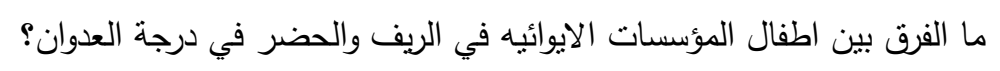

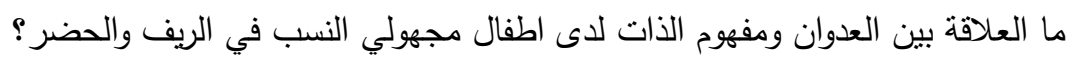




\section{أهمية التصراسة}

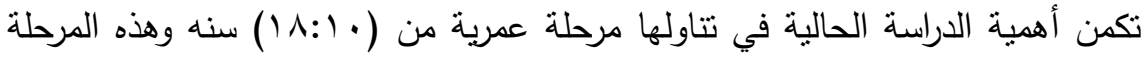

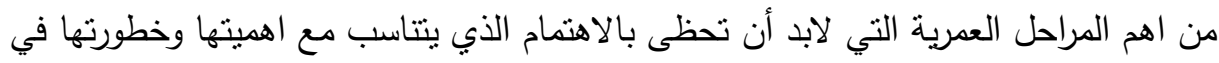

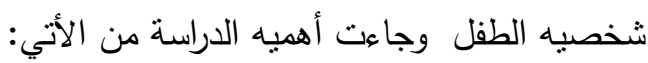

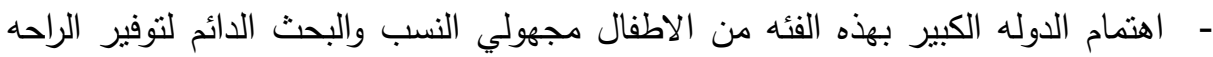

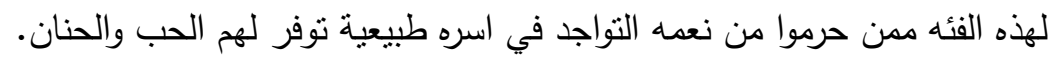

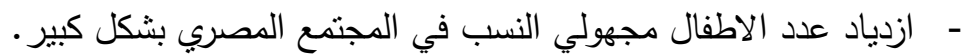

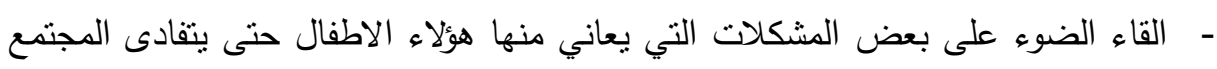

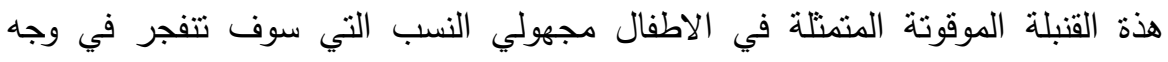
المجتمع ككل في صوره مشكلات عديدة النفيسة منها والاجتماعية اذا لم يتم احتواؤها وتحويلهم الى اعضاء نافعين لانفسهم ولمجتمعهم.

\section{أهساهث التوراسة}

- التعرف على أهم الشكلات النفسية والاجتماعية للاطفال مجهولي النسب داخل المؤسسات الايوائيه في الريف والحضر.

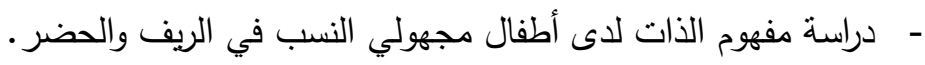

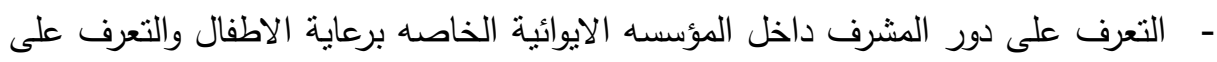
الاهيكل التتظيمي داخل المؤسسه وكيف يمكن أن يؤثر على الطفل. - معرفة طبيعة العلاقة بين مفهوم الذات والعدوان لاى أطفال المؤسسات الايوائية في الريف والحضر. - اقتراح بعض التوصيات للواجهة المشكلات الاجتماعية والنفسية لاى الطفل مجهولي

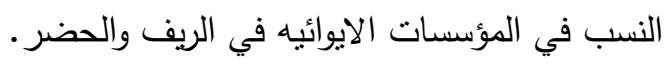




\section{هذاهميه التراسمة}

1-مفهوم الذات: تعريف برونو 9 19 ا يعرف مفهوم الذات بانه تقييم شامل عام للفرد عن شخصيتة وهو مستمد من التقييم الموضوعي عن طبيعة سلوكنا وبالنالي فان يكون سلبيا او ايجابيا

ץ-مفهوم مجهول النسب: يطلق على الطفل مجهول النسب مسميات متعدده منل اللقيط، مجهول الهوية ،مجهول الوالدين ويطلق عليه العاملين في المؤسسات الايوائيه طفل بديل.

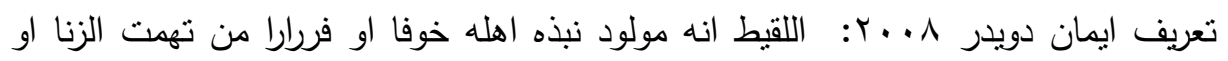
تعدد الاهمال وما شابه ذاللك . ب-مفهوم المؤسسات الايوائية: عرفت الموسسة الايوائية بأنها تجمع انساني بنتظم فيه الافراد ويشاركوا في تحقيق هدف مشترك ويكون لكل منهم دور ومسؤليه في تحقيق هذا الهذف.

ع-مفهوم العدوان: تعريف صابر حجازي عبد المولى ب991: هو سلوك يصدره الفرد

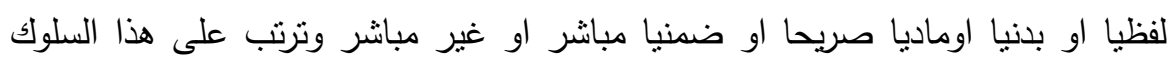
الحاق اذى بدني او مادي او نفسي للشخص نفسه صاحب السلوك التو او الاخرين ه-مفهوم المشكلات النفسيه: هي موقف يواجه الفرد تعز فية قدراتة عن مواجته بفاعيلية مناسبه او ان تصاب قدرة الفرد فجأه بعجز في امكانياتها بحيث يعجز عن نتاول

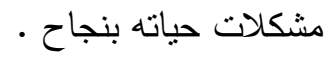
צ-مفهوم المشكلات الاجتماعية: هي عباره عن ظروف معينة في العالم الخارجي (البيئة) والتي يمكن فهمها على انها تمثل مضايقة او اضرار وتنتحق منا التنخل الاجتماعي. 


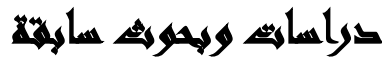

أولأ: الاراسات العربية:

ا - دراسة عبلة البدرى ( . . . ب) بعنوان: دور المشرف الاجتماعى وعلاقته بتكيف الاطفال فى المؤسسة الإيوائية.

هدفت الدراسة الى: التعرف على دور المشرف الاجتماعى بالمؤسسة الإيوائية وعلاقته بتكيف

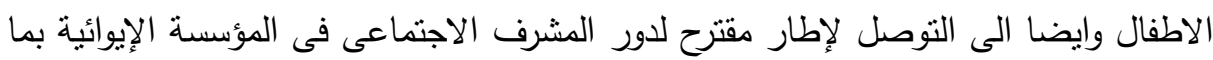

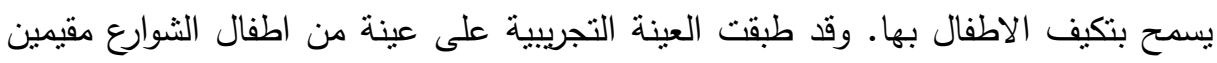

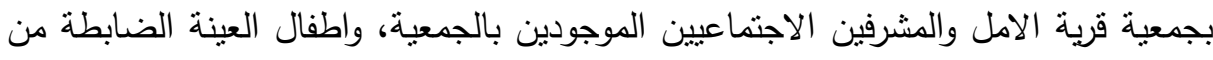
جمعية انقاذ الطفولة. واستخدمت الباحثة مقياس السلوك التكيفى للاطفال واستمارة المقابلة اللمشرفين كأدوات لدراستها. وقد توصلت الدراسة الى النتائج الآتية :

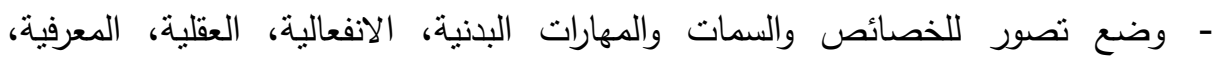
الاجتماعية، الخلقية، المهنية، التى يجب ان تتوفر فى المشرف الاجتماعى.

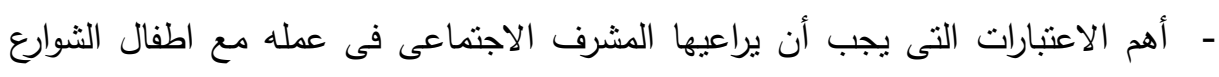
تتمثل فى استخدام اسلوب الممارسة العامة التى تهنم بالموقف والمشكلات الاجتماعية والحاجات الانسانية للانساق المختلفة التى يعمل معها المشرف الاجتماعى.

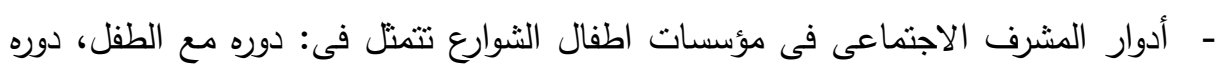

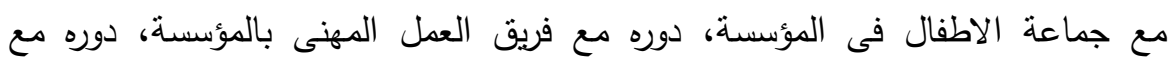
المؤسسة، دوره مع المجتمع.

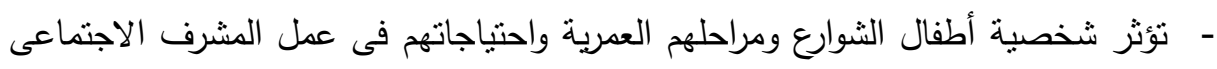

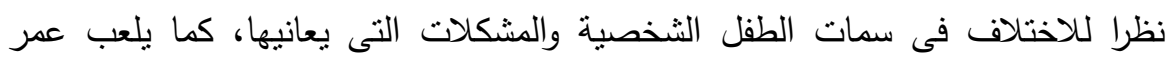

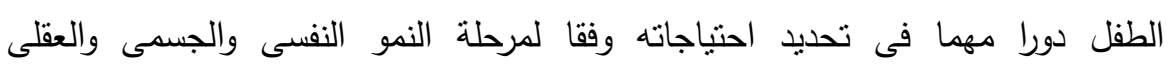

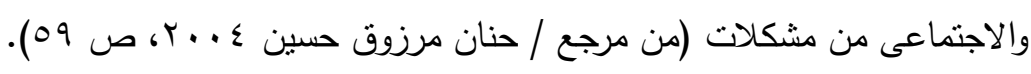


r- دراسة مها صلاح الاين محمد حسن (ب9919): عن "تقويم لبعض اسليب رعاية

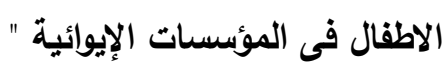

تهدف الى الدور التى تؤديه المؤسسات الإيوائية والمعوقات التى تواجه هذه المؤسيسات،

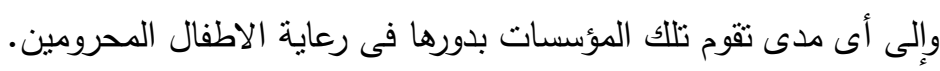

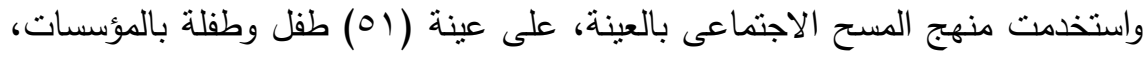

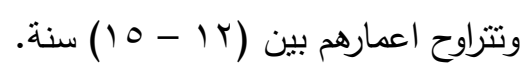

واستخدت الباحثة الأدوات الثالية: استمارة استيان للعاملين بالمؤسسات الإيوائية،

استمارة استبيان للاطفال الموجودين بالمؤسسات الإيوائية، مقياس مقنن للخبراء التنفيذيين.

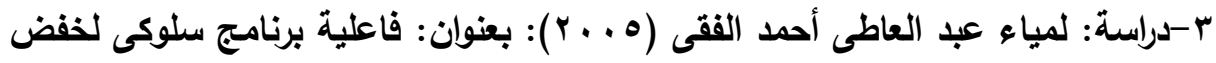
بصض المشكلات النفسية وتحقيق التوافق النفسى لاى أبناء المؤسسات الأيوائية:

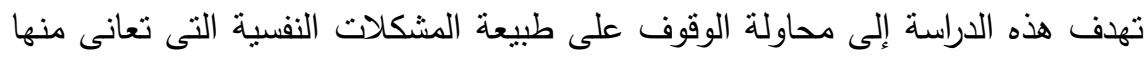
الآطفال بالمؤسسات الإيوائية وتحقيق التوافق النفسى لهم. وتوصلت الدراسة إلى أنه توجد فروق بين متوسطى درجات أفراد العينة قبل تطبيق

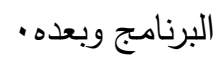

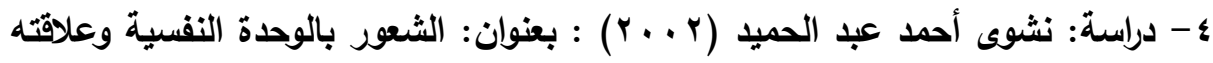

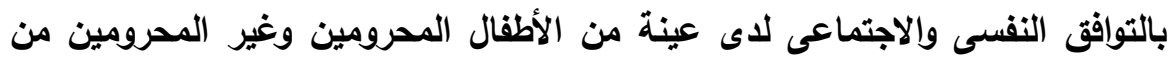

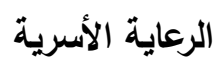

تهلف الدراسة الى التعرف على الفروق بين أطفال المدارس واطفال الؤُسسات الإيوائية

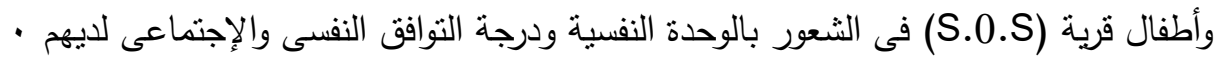

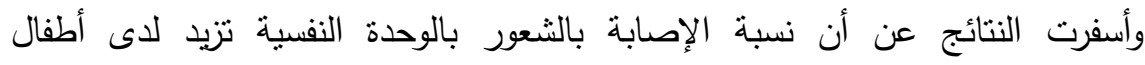
المؤسسات عنها لدى أطفال قرية ( s.0.s) وذلك نتيجة حرمانهم من الرعاية الوالدية ومنخفض لاى أطفال الأسر العادية. 


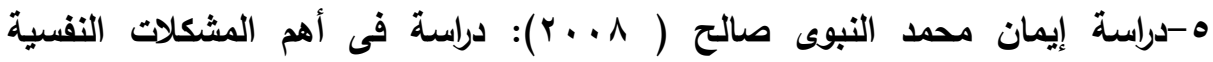
والاجتماعية لدى الأطفال مجهولى النسب فى الأسر البديلة والمؤسسات الإيوائية: تهدف الدراسة إلى التعرف على بعض وأهم المشكلات النفسية والإجتماعية للأطفال مجهولى النسب داخل الأسر البديلة، والأطفال مجهولى النسب داخل المؤسسات الإيوائية:

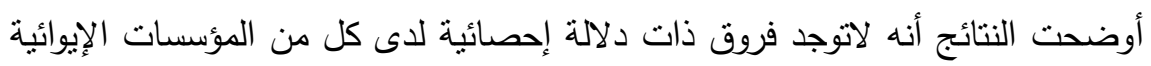
والأسر البديلة بين الذكور والأناث فى المشكلات النفسية والإجتماعية أكثر من الأطفال الإناث.

أن المشكلات النفسية والإجتماعية لا تقتصر فقط على أطفال المؤسسات دون غيرها من

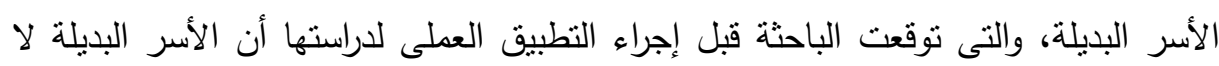

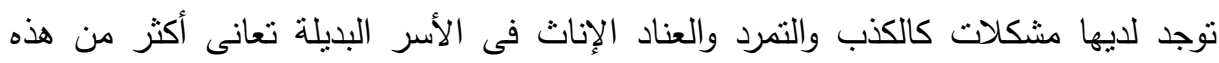
المشكلات من الإنات فى المؤسسات الإيوائية. ثانيًا: الاراسات الإجنبية

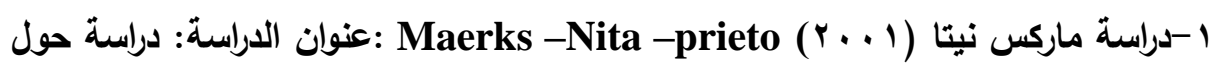
التنمية الأخلاقية لأطفال الثوارع الذين يعيثون في مؤسسات الإيواء

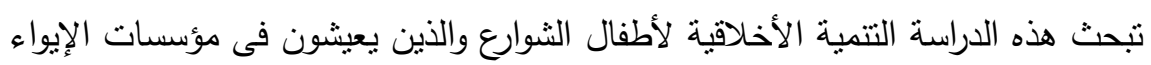
المؤقتة وتتثمل هذه الدراسة جوانب معينة من تلك التتمية الأخلاقية وهى الكذب - السرقة عدالة العقاب - فائدة العقاب المساواة تقابل السلطة واستخدمت الدراسة اختبار التتمية

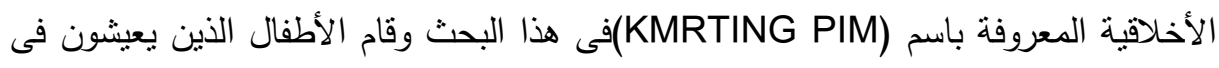

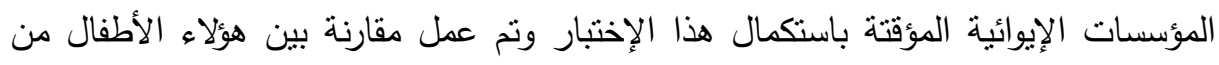

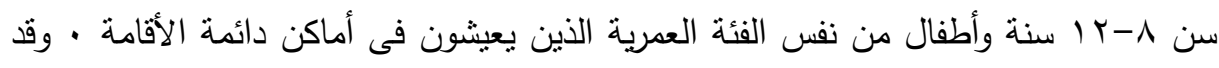
أكدت نتائج الدراسة على وجود فروق بين أطفال المؤسسات الإيوائية دائمة الإقامة وأطفال

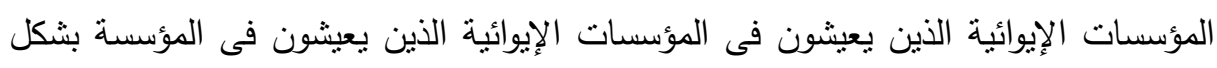

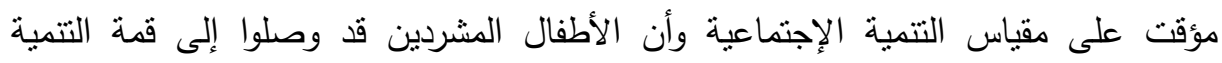


الأخلاقية فى سن ^ سنوات ثم نتضاءل بعد ذلك نتيجة لتواجد هم فى بيئة غير سوية تساعد على انعدام هذه التتمية الإجتماعية.

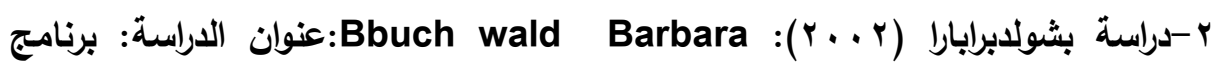

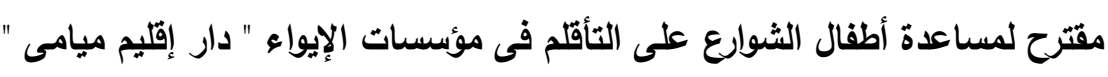

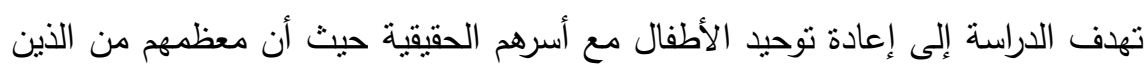
تعرضوا للإيذاء من قبل الوالدين أو الأوصياء عليهم غالبا ما يصابون بمشكلات الطات نفسية

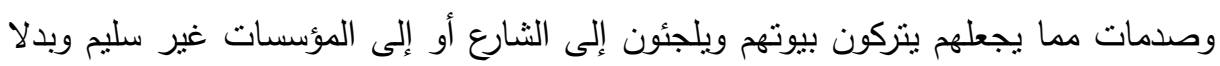

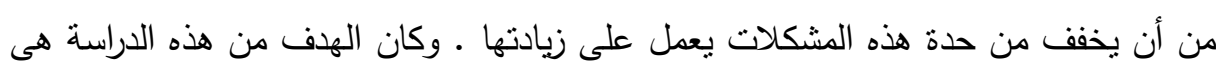

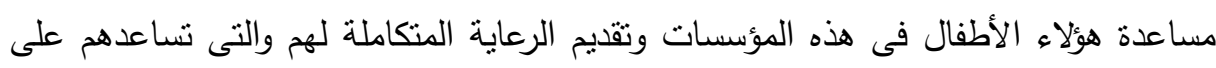
التغلب على المشكلات كما تحاول الدراسة أيضا حدوث رابطة قوية بين الأسر الحقيقية لهؤلاء

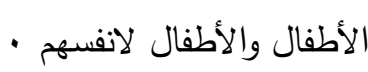
ويهذف هذا البرنامج إلى تقديم نموذج يؤسس جزءا ضخما يخص قاعدة عريضة من

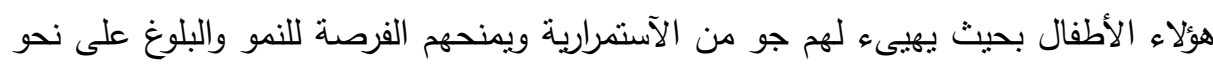
صحيح ويؤهلهم كذللك للنجاح والثعور بالسعادة . هون.

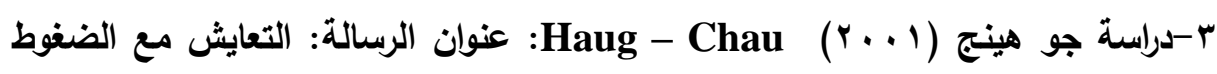
النفسية الخاصة بأطفال المؤسسات الإيوائية فى سن المدرسة

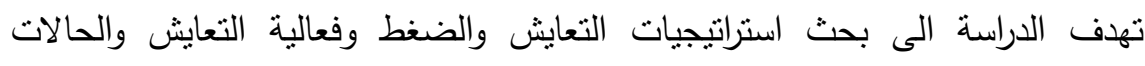

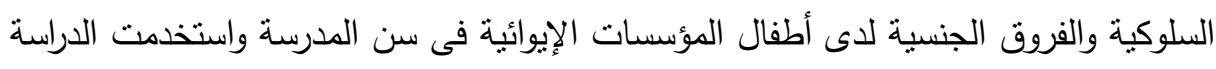

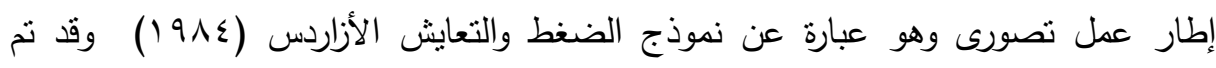

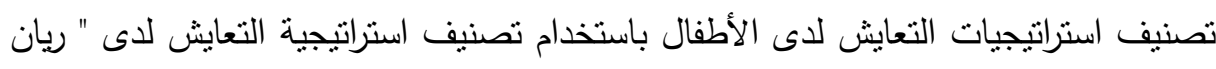

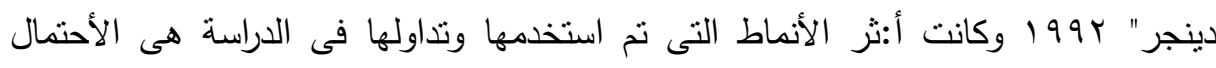
وتعديل الضاغط والدعم الإجتماعى والتعبيرالعاطفى والتجنب السلوكى والإضطراب السلوكى الأنى

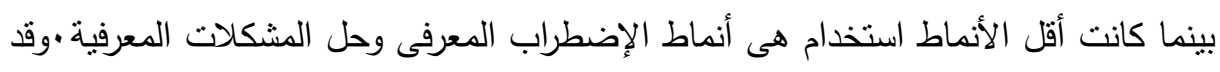

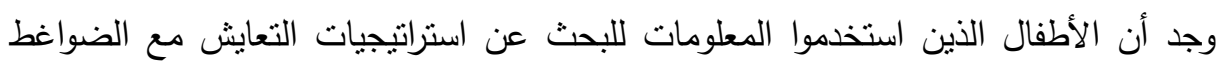

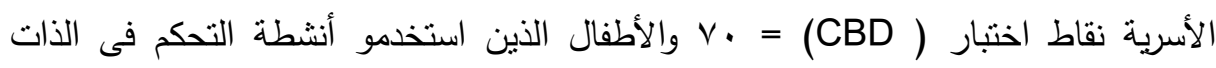


للبحث عن استراتيجيات التعايش مع الذات " نقاط اختبار (CBD) = § نقاط اختبار (CBD) للتدرج العلاجى.

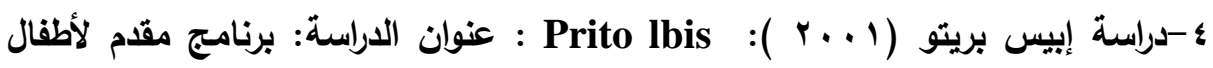

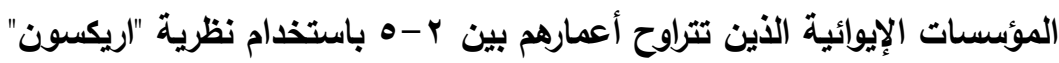

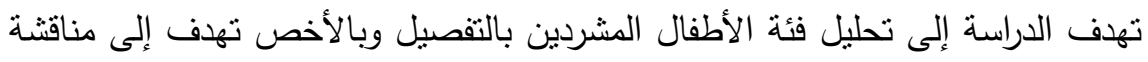

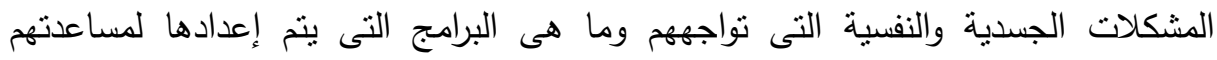

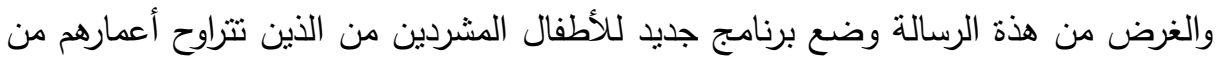

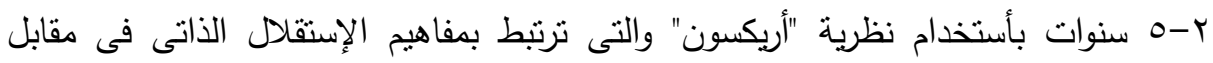

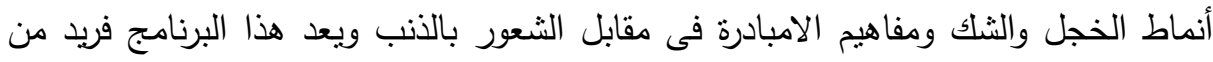
نوعه حيث تتكامل فيه كل هذه المجالات معا فى وقت واحد، ويحاول البرنامج منح هؤلاء الأطفال ببيئة تعليمية ونفسية مناسبة تصميم هذا البرنامج على منهج الطفل المشرد الجرأ'

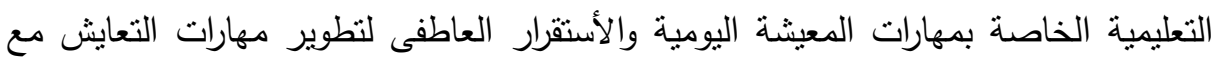

من حيث الهيف: التعرف على دور المثرف الاجتماعى بالمؤسسة الإيوائية وعلاقته بتكيف

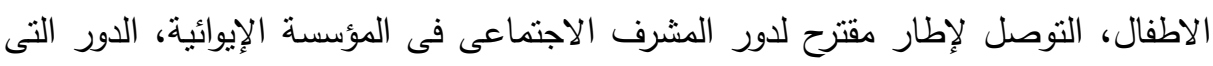

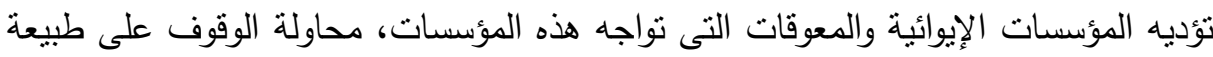

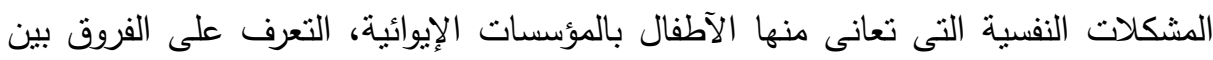
أطفال المدارس واطفال المؤسسات الإيوائية واطفال قرية (S.0.S) فى الثعور بالوحدة النفسية بالئه ودرجة التوافق النفسى والإجتماعى لديهم التعرف على بعض وأهم المشكلات النفسية

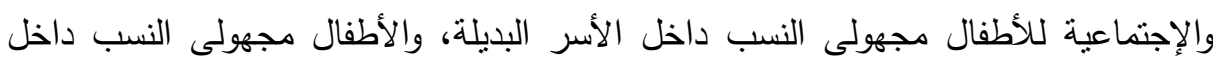

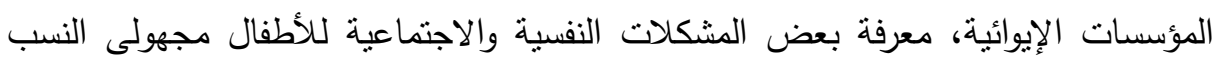

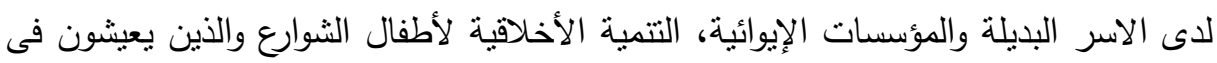

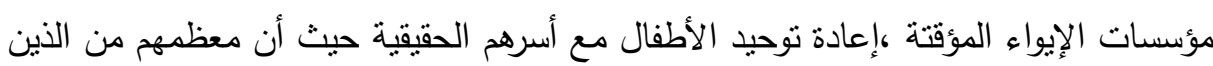

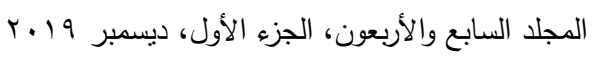


تعرضوا للإيذاء من قبل الوالدين أو الأوصياء ،بحث استراتيجيات التعايش والضغط وفعالية التعايش والحالات السلوكية والفروق الجنسية لدى أطفال المؤسسات الإيوائية فى سن المدرسة المناء من حيث مشكلة الاراسة: طرق تقويم لبعض اساليب رعاية الاطفال فى المؤسسات الإيوائية، ولئه الثعور بالوحدة النفسية وعلاقته بالتوافق النفسى والاجتماعى لدى لعضى عينة من الأطفال

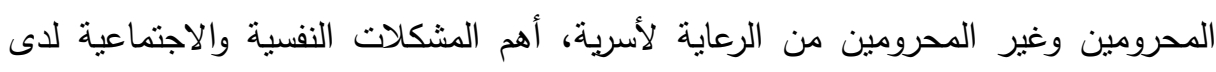

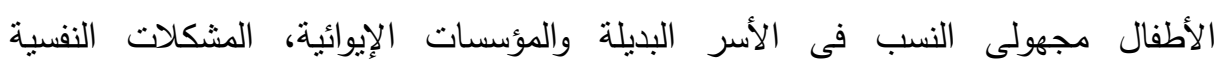

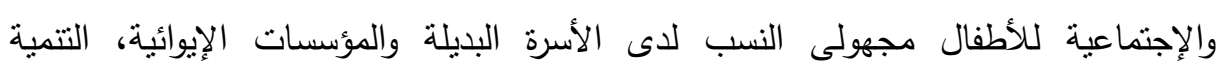

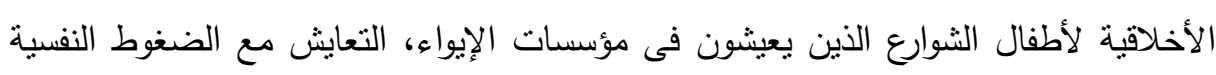

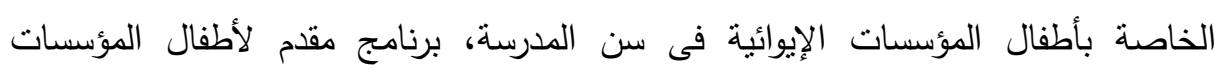

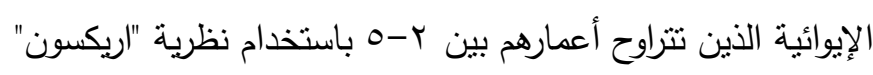

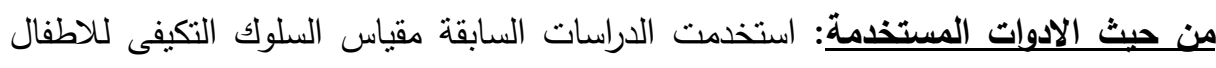

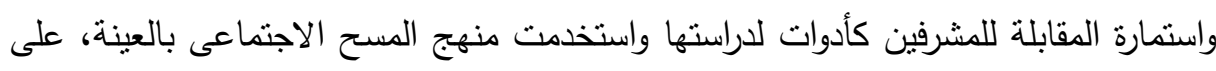

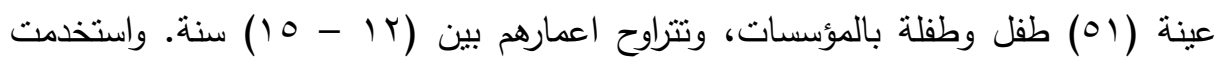
الباحثة الادوات التالية : استمارة استبيان للعاملين بالمؤسسات الإيوائية، استمارة استبيان

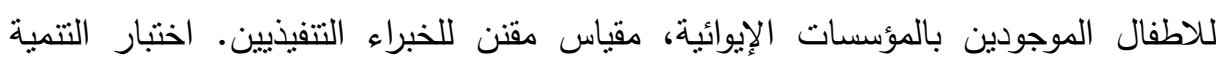

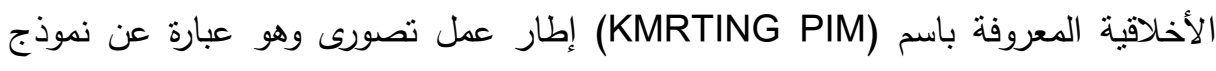
الضغط والتعايش الأزاردس (ع (91)) بأستخدام نظرية "أريكسون" والتى ترتبط بمفاهيم

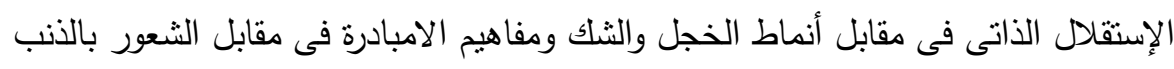
من حيث نتائج الدراسات السابقة: تؤثر شخصية اطفال الثوارع ومراحلهم العمرية واحتباجاتهم فى عمل المشرف الاجتماعى نظرا، الاختلاف فى سمات الطفل الثخصية والمشكلات التى يعانيها، كما يلعب عمر الطفل دورا مهما فى تحديد احتباجاته وفقا لمرحلة الهن النمو النفسى والجسمى والعقلى والاجتماعى من مشكلات، فضلا على تكوين علاقة اجتماعية

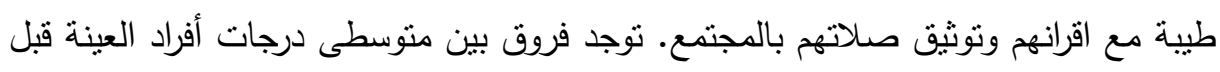

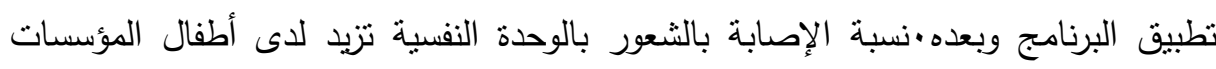

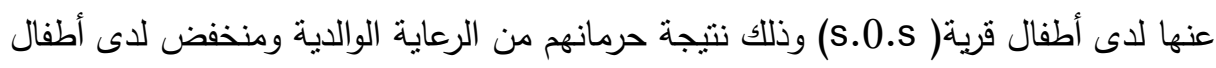


الاسر العادية •لاتوجد فروق ذات دلالة إحصائية لاى كل من المؤسسات الإيوائية والأسر

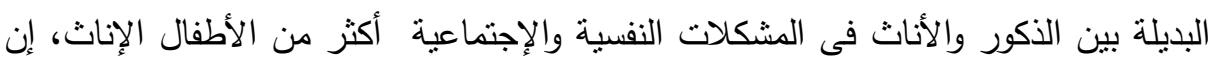
السمات المميزة للمودعين بالمؤسسات الإيوائية هى الثعور بالإثم والخجل والانطواء والخيال

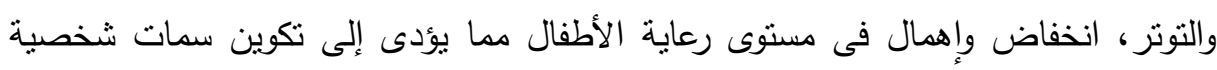

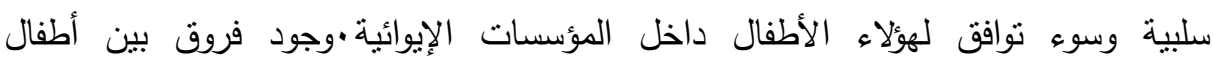

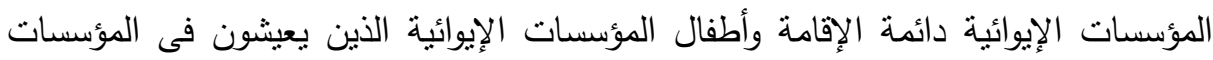
الإيوائية الذين يعيشون فى المؤسسة بشكل مؤقت على مقياس التتمية الإجتماعية.

\section{الاطار النظليه اللدراهم}

نظريات العدوان وأسبابه: تعددت النظريات التي تفسر العدوان والأسباب المؤديه له، الا

انه يمكن اجمال هذه النظريات في اربعة محاور اساسية هي :. ا. نظرية التحليل النفسي: تبعا لهذه النظريه فأن القوى المحركة لسلوك الانسان هي غرئه غريزة

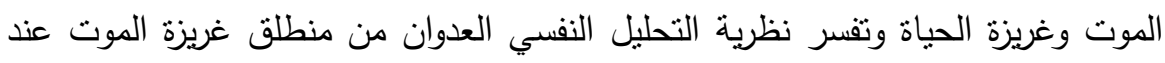
الانسان حيث انها نزعة الكراهية وعندما تجد هذه النزعة الطريق إلى التعبير يسيطر لهربه العنف على الانسان ـ أب ان الانسان عندما يشعر بتهديد خارجي نتتبه غريزته العدوانيه

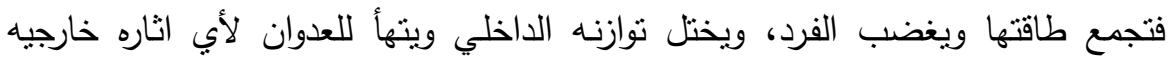
بسيطة، وقد يعتدي بدون آثارخارجيه حتى يفرغ طاقته العدوانية ويخفف نوتره النفسي،

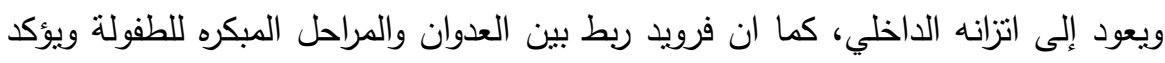

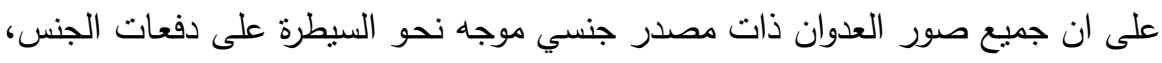
وذللك من خلال ربطها بالمراحل المختلفة للتطور النفسي للطفل. ثم أكد أدلر أحد تلادذة دونة فرويد على ان العنف والعدوان عبارة عن استجابة تعويضية عن الاحساس بالنقص براجس

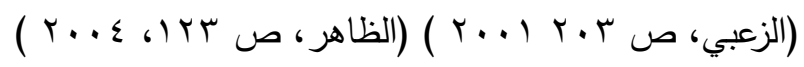

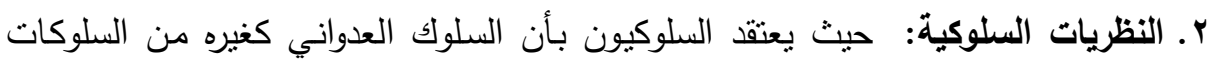

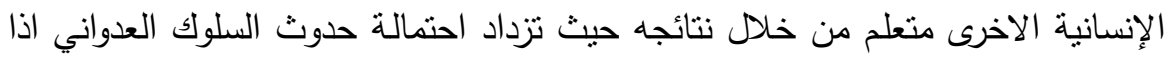

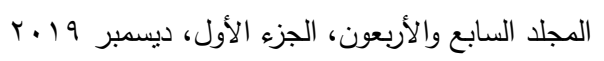


كانت نتائجه مطروحه والعكس صحيح، وهو منطلق نظرية الاشراط الاجرائي لسكنر أي

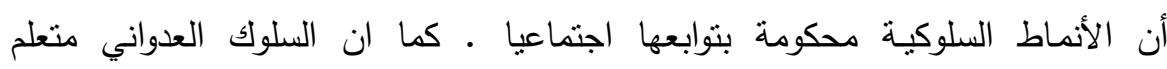
اجتماعيا عن طريق ملاحظة الاطفال نماذج العدوان عند والديهم ومدرسيهم وأصدقائهم وأفلام التلفزيون وفي القصص التي يقرأونها كما ان لاساليب التتشئة الاجتماعية دور كبير

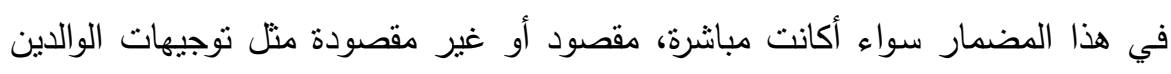

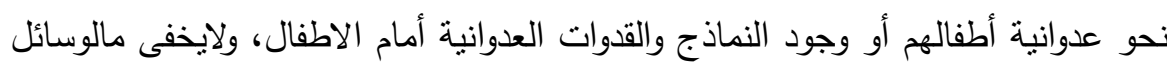
الاعلام من دور كبير في هذا الثأن، لأن احساس وادراك الطفل بعتمد في المقام الأول

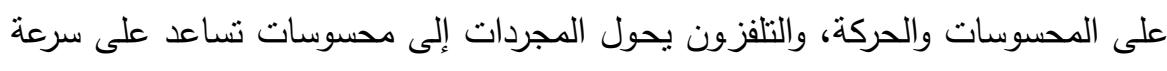

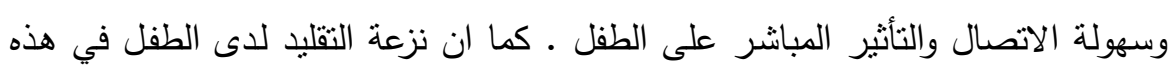

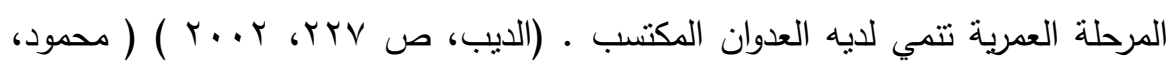

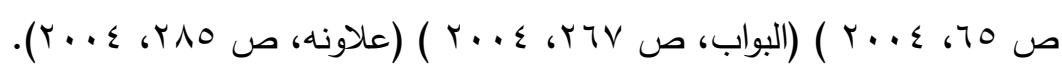

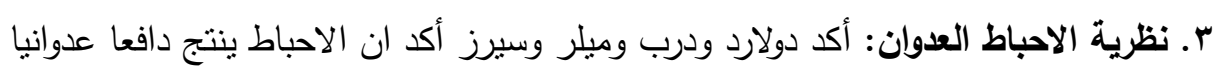

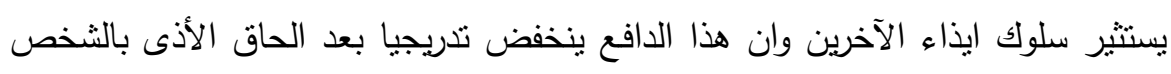

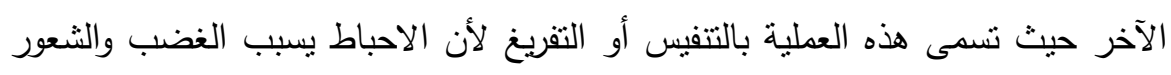

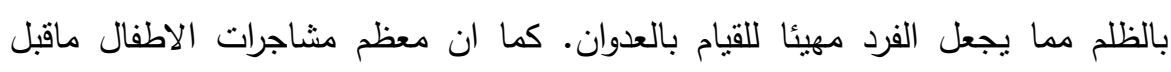

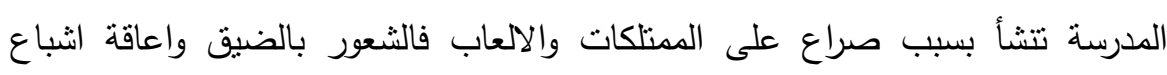

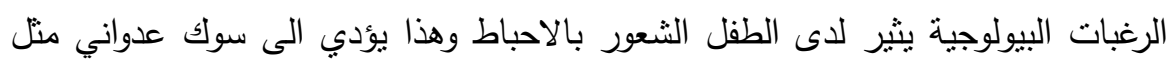

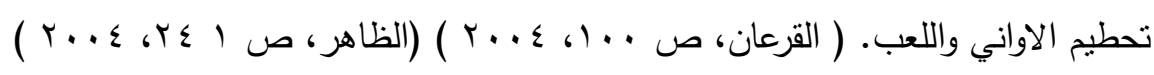

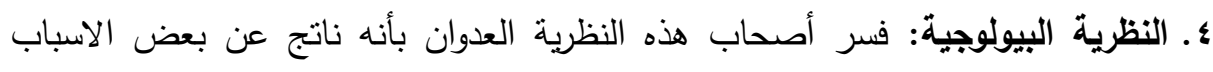
الجسمية والداخلية ولاسيما منطقة الفص الجبهي في المخ كونها المسؤولة عن ظهور

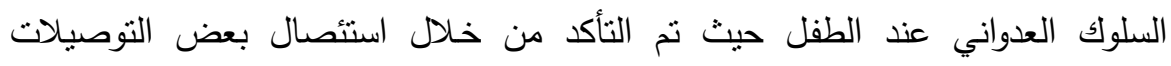
العصبية في هذه المنطقة عن المخ أدى ذلك إلى خفض التوتر والغضب والميل للعنف وأكد علماء آخرين على ان بعض العوامل الجسمية مثل التعب أو الجوع أو وجود آلام

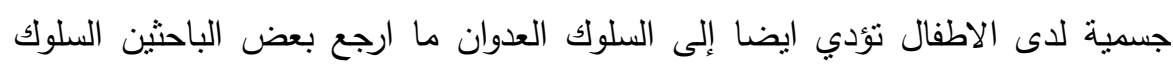

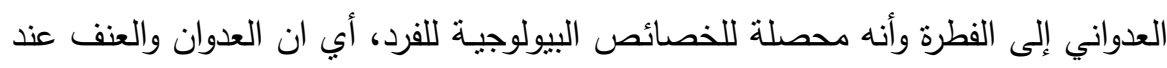


الانسان يتضمن نظاما غريزيا، وأنه يعتدي لأشباع حاجاته لفطرية للتملك والدفاع عن

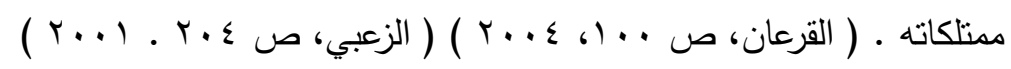

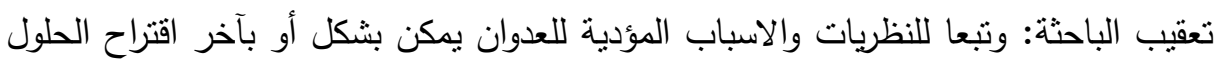

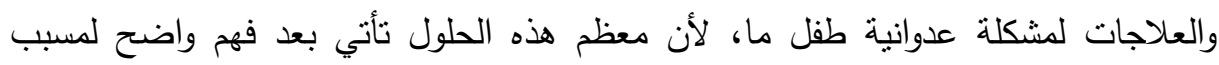

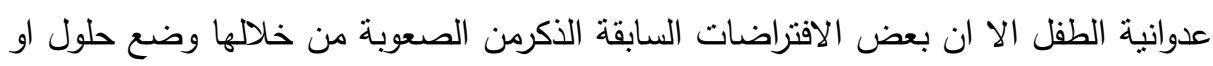

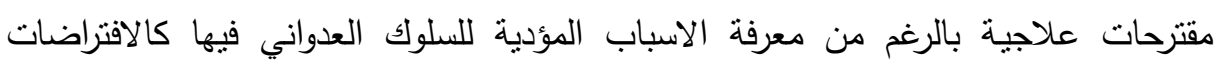
البيولوجية الني قد يفيد في ضوئها وضع بعض العلاجات المادية أو الدوائية، أما بالنسبة

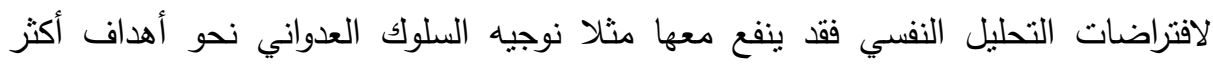

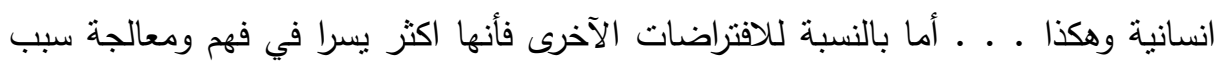
العدوان بالاتجاه السلوكي والنفسي أو تحديد مساللك تربوية في علاج عدوانية طفل ما.

\section{إجراءاهي التراسه}

وتتضح اجراءات الدراسة من خلال تتاول الآتي: عينة الدراسة: يعد هذا أمرا ضروريا لان هذا يحدد الاسلوب العلمي الامثل لدراسة هذا المجتمع مفهوم الذات والعدوان لدى الاطفال مجهولي النسب.

العينة المختارة :وقد روعي عند أختيار عينة الدراسة أن تنوافر فيها الثروط الأبعاب التالية:

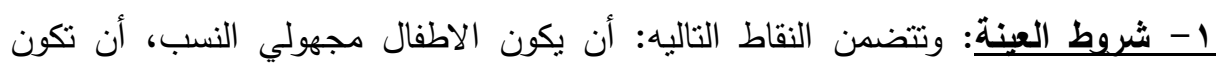
مفردات العينة من سكان ( ريف وحضر)، نم اختيار مفردات العينة من مراكز الايوائية

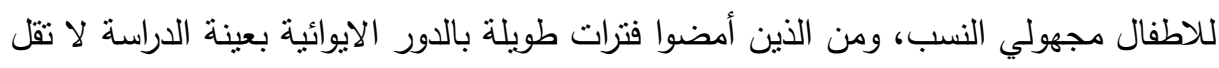
عن ست سنوات. r ب نوع الدراسة: تعد هذه الدراسة دراسة وصفية تحليلية.

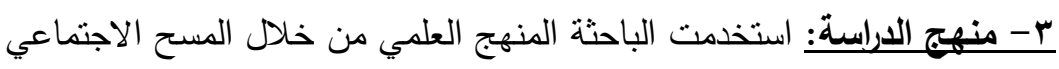


ع -عينة الدراسة وخصائصها: وتضمنت (0؛ مفردة من الاطفال مجهولي النسب بالمؤسسات الايوائية بمحافظة القاهرة والمنوفية) نم أخذها باسلوب العينة العشوائية ائية موزعين

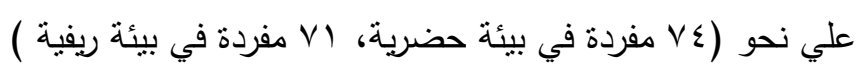

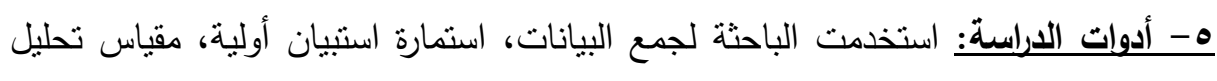
الذات ( إعداد الباحثون) مع الاستعانة بالدراسات والبحوث السابقة.

حدود الاراسة: إعاد أ) المجال البشرى: ويقصد بالمجال البشرى للدراسة او عينة الدراسة بمفردات البحث التى

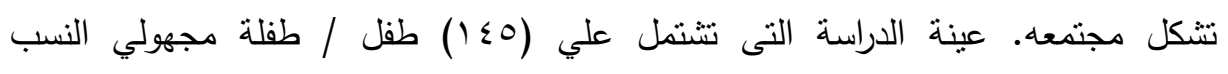
بالمؤسسات الايوائية بالريف والحضر بمحافظتي القاهرة والمنوفية .

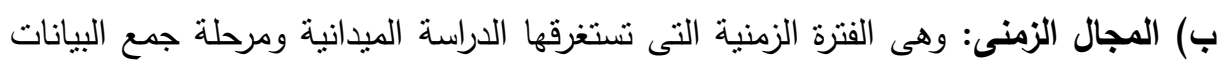

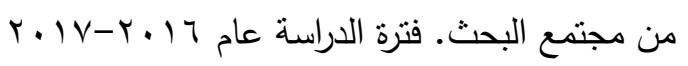

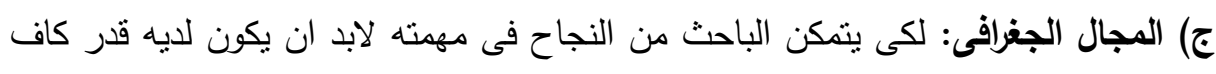

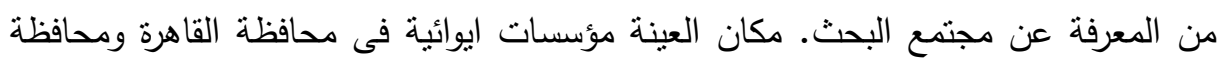
المنوفية.

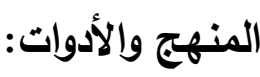

أدوات الدراسة: يتوقف اختيار الاداة اللازمة لجمع البيانات على عدة عوامل وقد استعان

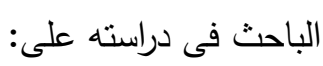
1-الملاحظة. ب-المقابلة الموجهة. ب-الوثائق والسجلات الرسمية. ع ع-اختبار السلوك

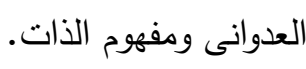

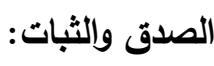
حساب ثبات المقياس: للتحقق من ثبات المقياس لإمكانية الاعتماد على نتائج المقاييس

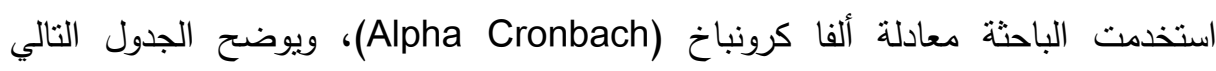
معاملات الثبات 
جدول (1): إثبات العبارات لأبعاد مقياس تقدير الذات لدي أطفال الايواء بالمؤسات الاجتماعية بعينة الدراسة

\begin{tabular}{|c|c|c|}
\hline 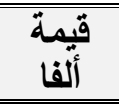 & العبارات & أبعاد المقياس \\
\hline$\cdot, \wedge \leq 0$ & $\Lambda$ & 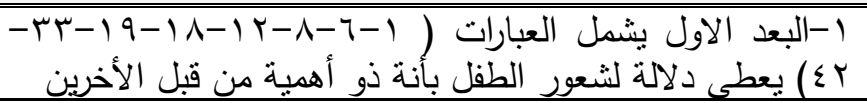 \\
\hline$\cdot, \vee \vee 9 Y$ & 1. & 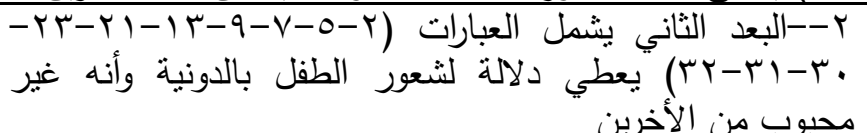 \\
\hline$\cdot, \vee \vee \neg$ & V & 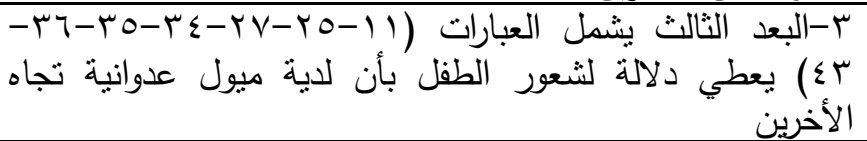 \\
\hline ', & 1. & 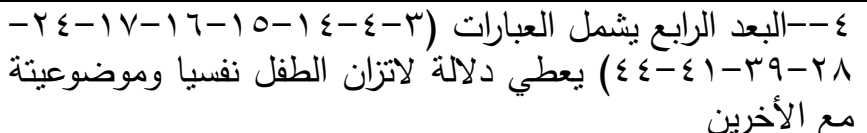 \\
\hline$\cdot, 9 \cdot 1$ & 1. & 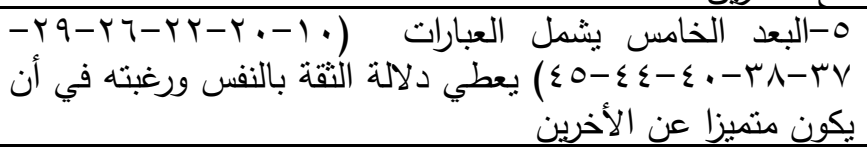 \\
\hline 947 & $\varepsilon 0$ & أجمالى المقياس \\
\hline
\end{tabular}

المصدر: جمعت وحسبت من بيانات عينة الدراسة

اتضح من الجدول السابق أن قيم دعاملات الثبات لأبعاد مقياس تقدير الذات جميعها قيم

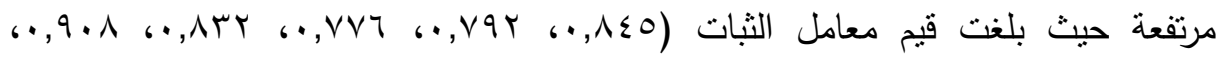

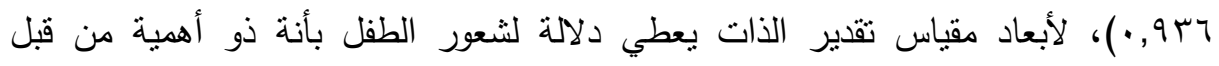

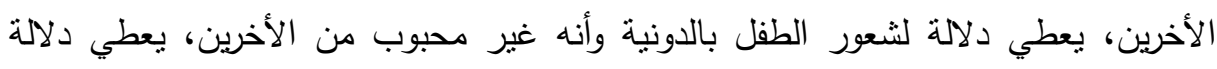
لشعور الطفل بأن لدية ميول عدوانية تجاه الأخرين، يعطي دلالة لاتزان الطفل نفسيا

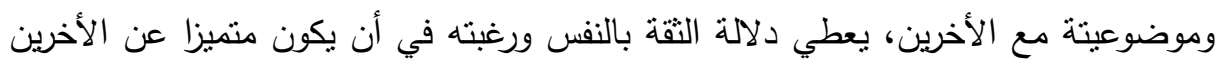

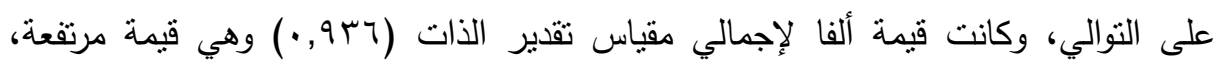
وتثير هذه القيم من معاملات الثبات إلى صلاحية العبارات وإمكانية الاعتماد على نتائجها 


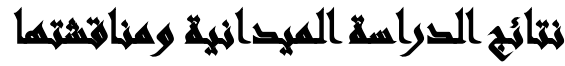

تعرض الباحثة في هذا الفصل النتائج الني خرجت بها الدراسة في ضوء المحددات التي

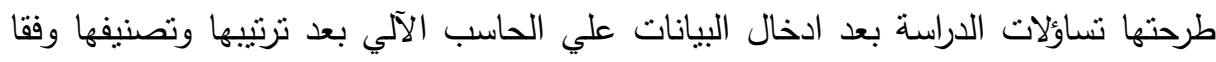

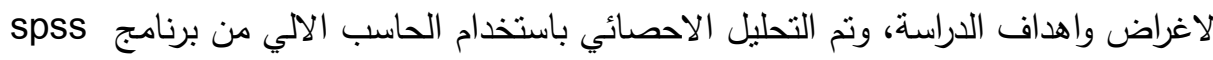

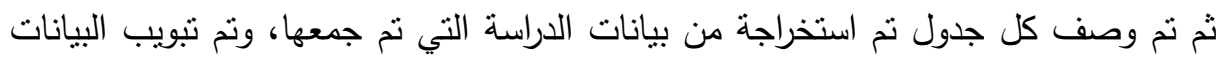
وتم استخدام الأساليب الاحصائية التالية: - الاحصاءات الوصفية للبيانات من خلال جدولة وترقيم وترميز البيانات في صورة جداول تكرارية ( التكرارات والنسب المئوية للمقياس والمتغيرات الاخري المرتبطة بالدراسة) - التحليل الاحصائي باستخدام العلاقات الارتباطية مثل معامل ارتباط بيرسون. - - التحليل الاحصائي باستخدام اختبار (ت). عرض نتائج الاراسة

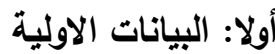
السن: جدول (1) الفئات العمرية لعينة الدراسة

\begin{tabular}{|c|c|c|c|}
\hline الاهمية النسبية & العدد & فئات السن & المتغير \\
\hline$\mu_{1, \cdot \varepsilon}$ & «o & من ع الى أقل من · اسنوات & \multirow{4}{*}{ فئات السن } \\
\hline$r \varepsilon, \varepsilon \wedge$ & 0. & من · 1 الى أقل من 10 سنوات & \\
\hline$r \varepsilon, \varepsilon \wedge$ & 0. & من 0 اسنوات فاكثر & \\
\hline $1 \ldots$ & $1 \leqslant 0$ & الاجمالى & \\
\hline
\end{tabular}

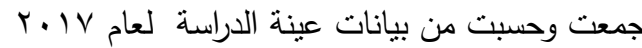

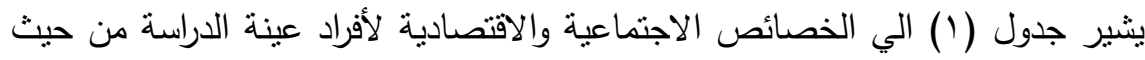
الفئات العمرية اذ نم تقسيم للاطفال المختارين الي ثلاث فئات تتتاول الفئة الاولي الاطفال

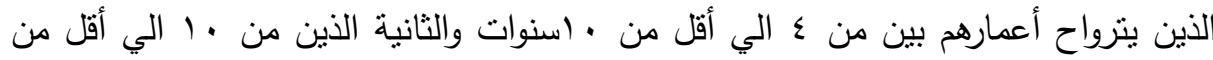
10 سنوات والثالثة من 0 اسنوات فاكثر وبتوزيع للاطفال المختارين وفقا لعينة الدراسة ينتين

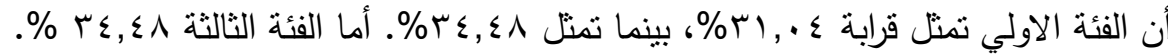

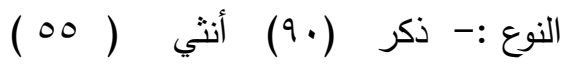


جدول (ץ): الحالة النوعية لافراد عينة الدراسة

\begin{tabular}{|c|c|c|c|}
\hline الاهمية النسبيةة & العدد & النوع & المتغير \\
\hline$r v, r q$ & 9. & ذكر & \multirow{3}{*}{ النوع } \\
\hline$T r, \cdot V$ & 00 & أنثى & \\
\hline $1 \ldots$ & $1 \leq 0$ & الاجمالل & \\
\hline
\end{tabular}

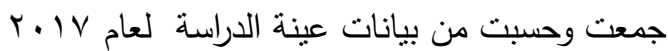

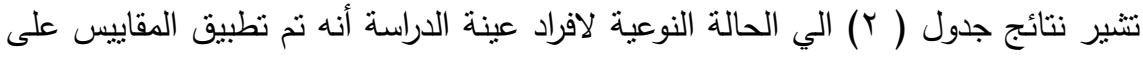

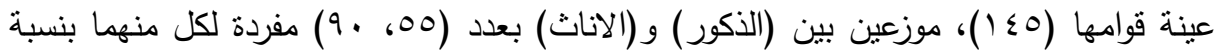

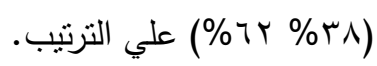

جدول (ץ): فترة وجود الطفل في المؤسسة

\begin{tabular}{|c|c|c|c|}
\hline الاهمية النسبية & العدد & فترة وجود الطقل في المؤسسة & المتغير \\
\hline$\varepsilon 0,0 Y$ & 77 & من 0 الي · ا سنوات & \multirow{3}{*}{ 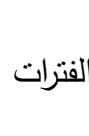 } \\
\hline $.0 \leqslant, \leqslant \Lambda$ & $\vee 9$ & أكثر من · 1 سنوات & \\
\hline $1 \ldots$ & $1 \leqslant 0$ & الإجمالى & \\
\hline
\end{tabular}

جمعت وحسبت من بيانات عبنة الدراسة لعام r. TV

فترة وجود الطفل في المؤسسة: تثنير بيانات جدول (؟r) الي فترة وجود الطفل في المؤسسة

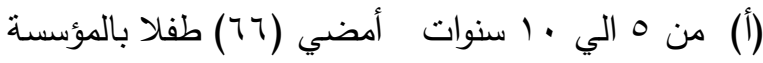

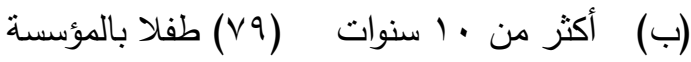
نظام الرعاية في المؤسسة تثير بيانات جدول (ع) الي نظام الرعاية في المؤسسة

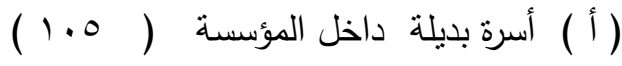

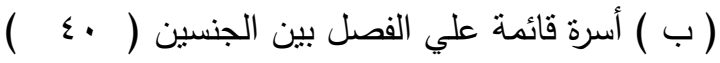
جدول (ع): نظام الرعاية في المؤسسة

\begin{tabular}{|c|c|c|c|}
\hline الاهمية النسبية & العدد العداد & نظام الرعاية في المؤسسة & المتغير \\
\hline$\overline{V Y, \&)}$ & 1.0 & أسرة بديلة & \multirow{3}{*}{ نظام الرعاية فى } \\
\hline$r V, 09$ & $\varepsilon$ & سرة قائمة علي الفصل بين الجنسين & \\
\hline$\ldots$ & $1 \leqslant 0$ & الإجمالى & \\
\hline
\end{tabular}

جمعت وحسبت من بيانات عينة الدراسة لعام IV 
نظام الرعاية في المؤسسة: تشير بيانات جدول ( ع) الي نظام الرعاية في المؤسسة حيث

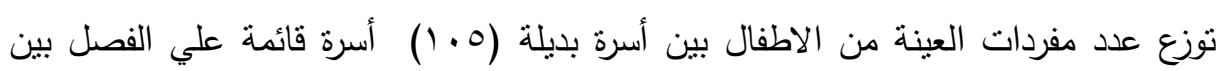

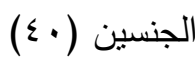

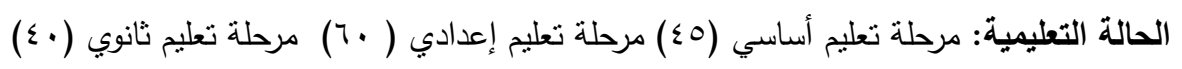
جلول (•) إلحالة التعليمية

\begin{tabular}{|c|c|c|c|}
\hline الاهمية النسبية & العدد & الحالة التعليمية & المتغير \\
\hline$\overline{\mu 1, \cdot r}$ & $\varepsilon 0$ & مرحلة تعليم أساسي & \multirow{4}{*}{ الحالة التعليمية } \\
\hline$\sum 1, \Gamma \wedge$ & 7. & مرحلة تعليم إعدادي & \\
\hline$r v, 0 q$ & $\varepsilon$. & مرحلة تعليم ثانوي & \\
\hline $1 \ldots$ & $1 \leq 0$ & الإجمالي & \\
\hline
\end{tabular}

جمعت وحسبت من بيانات عينة الدراسة لعام V IV

درجة تعليم المبحوث: وقد تم قياس ذلك المتغير بسؤال الاطفال المبحوثين عن درجة تعلئ تعليمة

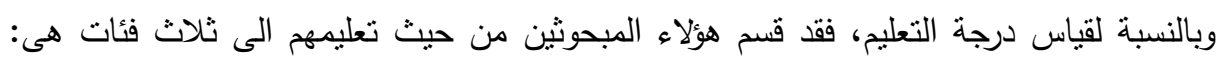

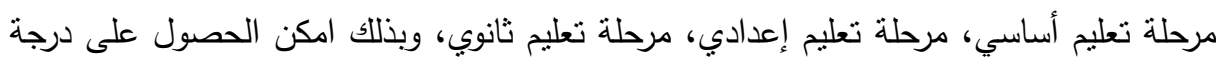

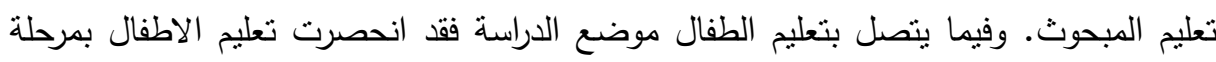

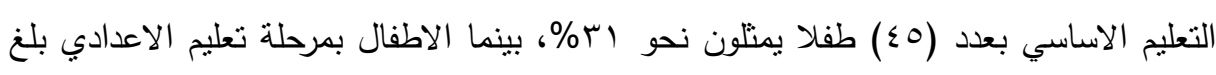

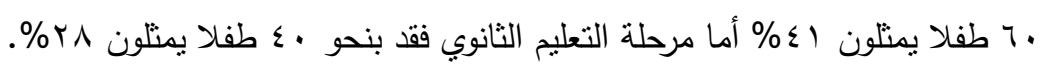

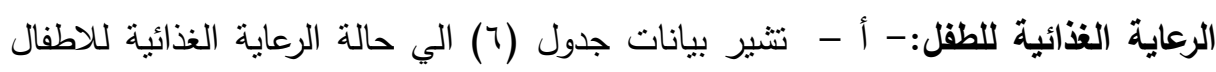
بالمؤسسات الايوائية من عدد مرات نتاول اللحوم في الاسبوع فكانت علي النحو التالي:

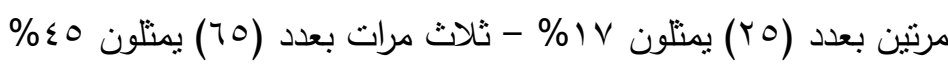

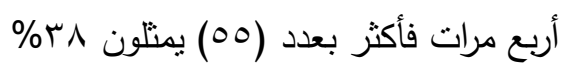

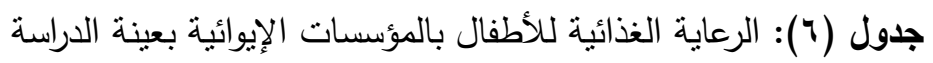

\begin{tabular}{|c|c|c|c|}
\hline الاهمية النسبية & العدد & كم مرة يتم تتاول البروتين * في الاسبوع & المتغير \\
\hline$I V, Y \leq$ & ro & مرتين & \multirow{4}{*}{ الرعاية الغذائية للطفل } \\
\hline$\varepsilon \varepsilon, \lambda \Gamma$ & 70 & ثلاث مرات & \\
\hline$r v, q \mu$ & 00 & أربع مرات فأكثر & \\
\hline $1 \ldots$ & $1 \leq 0$ & الإجمالى & \\
\hline
\end{tabular}


ب- تثير بيانات جدول (V) الي مستوي الطعام الذي يتم تقديمة للاكل للاطفال المقيمين

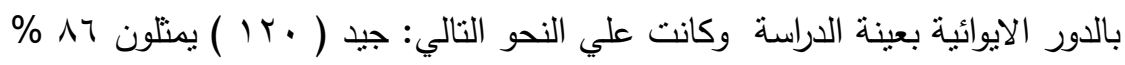

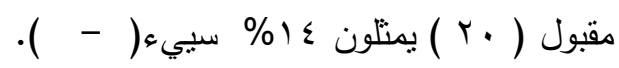
جدول (V): مستوي الطعام الذي يتم تقديمة للاكل

\begin{tabular}{|c|c|c|c|}
\hline النسبة & العدد & مستوي الطعام & المتغير \\
\hline$\langle\tau, Y)$ & Iro & جيد & \multirow{4}{*}{ مستوي الطعام الذي يتم تقديمة } \\
\hline $1 \Gamma, \vee 9$ & $r$. & مقبول & \\
\hline- & - & سيبs & \\
\hline $1 \ldots$ & $1 \leqslant 0$ & الإجمالى & \\
\hline
\end{tabular}

جمعت وحسبت من بيانات عينة الدراسة لعام Y.IV ثانيا - مفاتيح مقياس تحليل الذات: جدول (^): ثبات العبارات لأبعاد مقياس تقدير الذات لدي أطفال الايواء بالمؤسسات الاجتماعية بعينة الدراسة

\begin{tabular}{|c|c|c|}
\hline قيمة ألفا & 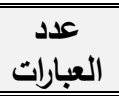 & أبعاد المقياس \\
\hline$\cdot, \wedge \leqslant 0$ & $\Lambda$ & 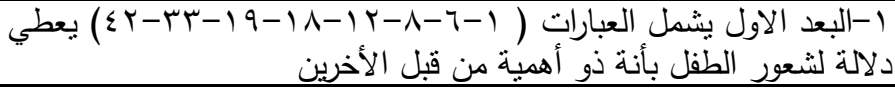 \\
\hline •, V१५ & 1. & 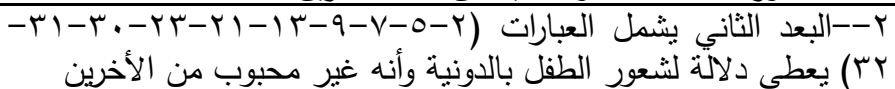 \\
\hline$\cdot, \vee \vee \vee 4$ & $\mathrm{~V}$ & 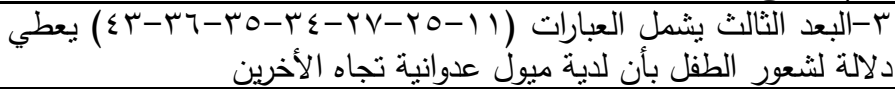 \\
\hline ( & 1. & 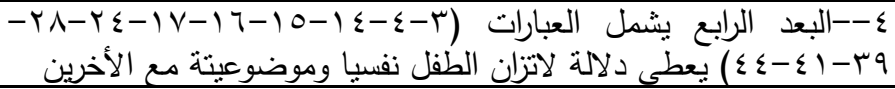 \\
\hline$\cdot, 9 \cdot 1$ & 1. & 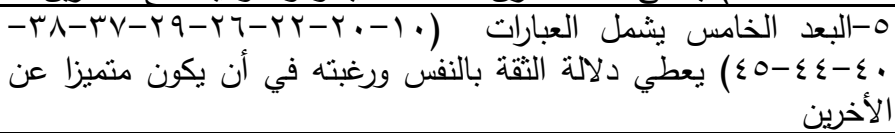 \\
\hline 947 & $\leq 0$ & إجمالى المقياس \\
\hline
\end{tabular}

اتضح من الجدول السابق أن قيم معاملات الثبات لأبعاد مقياس تقدير الذات جميعها قيم

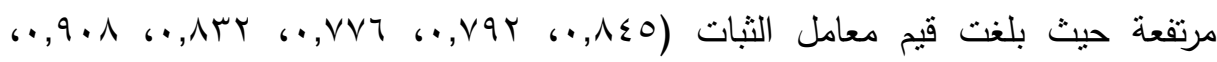
جrq, •)، لأبعاد مقياس تقدير الذات يعطي دلالة لثعور الطفل بأنة ذو أهمية من قبل 
الأخرين، يعطي دلالة لشعور الطفل بالدونية وأنه غير محبوب من الأخرين، يعطي دلالة

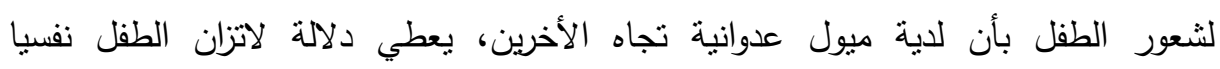

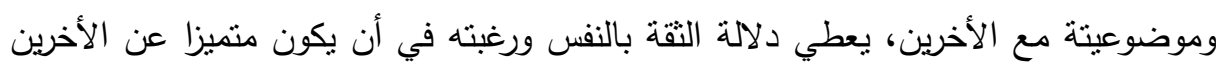

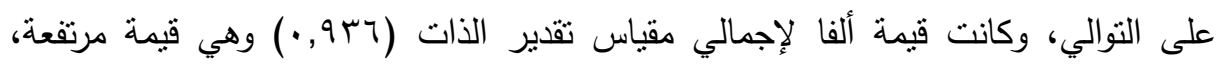
وتتير هذه القيم من معاملات الثبات إلى صلاحية العبارات وإمكانية الاعتماد على نتائجها

والوثوق بها.

نتائج مقياس تحليل الأت:

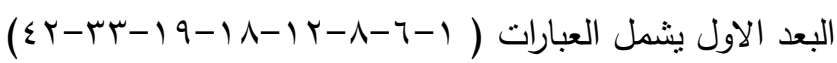
جدول (9): النسب المئوية لعبارات البعد الاول يعطي دلالة لثعور الطفل بأنه ذو أهية من

\begin{tabular}{|c|c|c|c|c|c|}
\hline$\%$ & مناسيرة & $\%$ & مناسبة & 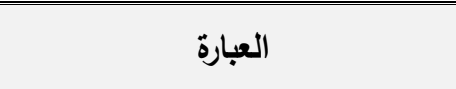 & b \\
\hline 89.66 & 130 & 10.34 & 15 & أنا شخص جذاب & $1 \overline{11}$ \\
\hline 75.86 & 110 & 24.14 & 35 & أنا شخص لطيف & 7 \\
\hline 68.97 & 100 & 31.03 & 45 & أنا شخص محبوب من قبل الاخربن & $\Lambda$ \\
\hline 75.86 & 110 & 24.14 & 35 & أنا شخص مهم في نظر من حولى & Ir \\
\hline 86.21 & 125 & 13.79 & 20 & أنا مصدر سعادة للاخرين & 11 \\
\hline 62.07 & 90 & 37.93 & 55 & أنا شخص ذكى & 19 \\
\hline 75.86 & 110 & 24.14 & 35 & أنا شخص محبوب & r \\
\hline 75.86 & 110 & 24.14 & 35 & أنا شخص مرح & $\varepsilon r$ \\
\hline
\end{tabular}

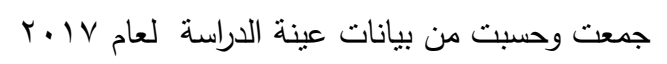

جدول (• (1): اختبار ( ت ) للفروق بين أجابات العبارات للمقياس

\begin{tabular}{|c|c|c|}
\hline غير مناسبة & مناسبة & المتغيرات \\
\hline 110.63 & 34.38 & المتوسط \\
\hline 160.27 & 160.27 & التباين \\
\hline \multirow[t]{5}{*}{8} & 8 & عدد المشاهدات \\
\hline & -1 & معامل بيرسون \\
\hline & 0 & Hypothesized Mean Difference \\
\hline & 7 & Df \\
\hline & -8.51788 & t Stat \\
\hline
\end{tabular}


وصف الجدول: من جدول التكرارات والنسب المئوية لاجابات عبارات نتير نتائج مقياس

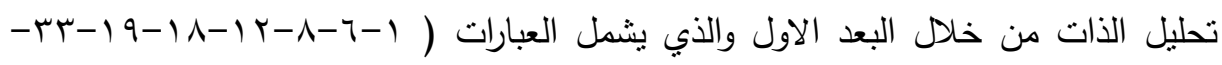

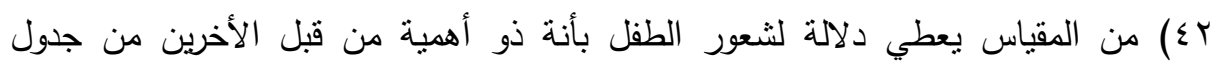

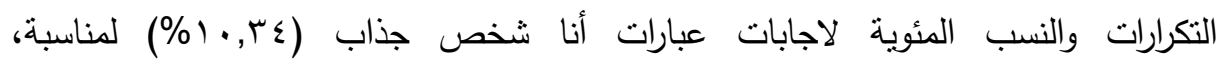

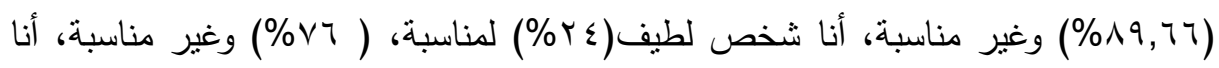
شخص محبوب من قبل الاخرين( ابr\%) لمناسبة، (

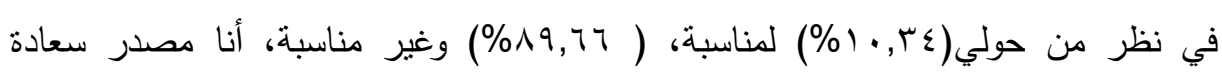

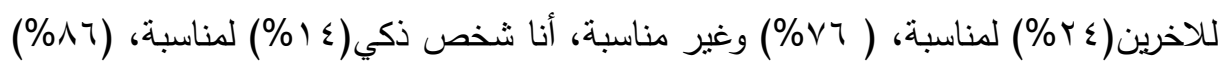

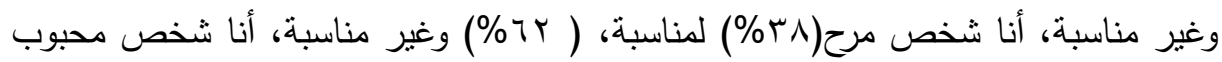

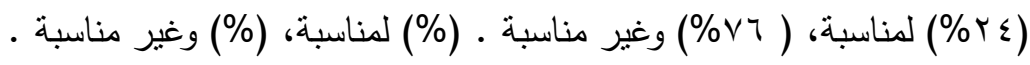

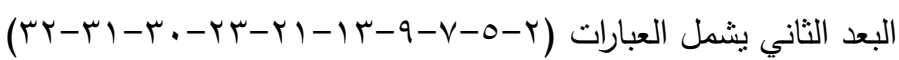

جدول (11): النسب المئوية للبعد الثاني يعطي دلالة لشعور الطفل بالدونية وأنه غير محبوب من الأخرين

\begin{tabular}{|c|c|c|c|c|c|}
\hline$\%$ & مناسبة & $\%$ & مناسبة & العبارة & r \\
\hline 88.28 & TYA & 111.72 & $\overline{I V}$ & أنا شخص مهذب & $\bar{\mu}$ \\
\hline 68.97 & $1 \ldots$ & 31.03 & $\leqslant 0$ & أشعر بأنني بلا قبمة & 0 \\
\hline 75.86 & 11. & 24.14 & ro & آقول الصدق دائما & $\mathrm{V}$ \\
\hline 82.76 & Ir. & 17.24 & ro & زملائي بأن أخلاقي لا ترقي لمستوي & 9 \\
\hline 68.97 & $1 \ldots$ & 31.03 & $\leqslant 0$ & أَشُعر بأننى بحاجة الى تغيير مظهري & $\pi$ \\
\hline 86.21 & TYO & 13.79 & r. & أنظر لنفسى باحتقار & TI \\
\hline 62.07 & 9. & 37.93 & 00 & الناس لا يعاملوني كما يجب & $T \mu$ \\
\hline 88.28 & TYA & 11.72 & IV & آغير رايي في آي موضوع & $\Gamma$. \\
\hline 68.97 & $1 \ldots$ & 31.03 & $\leqslant 0$ & أشُعر بأن الناس أفضل منى & $\bar{T}$ \\
\hline 75.86 & 11. & 24.14 & $\mu_{0}$ & لست راضي عن وضعى الحالى & TY \\
\hline
\end{tabular}

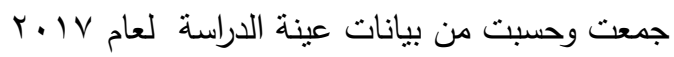


جدول (r ا): اختبار ( ت ) للفروق بين أجابات العبارات للمقياس

\begin{tabular}{|c|c|c|}
\hline غير مناسبة & مناسبة & المتغيرات \\
\hline 111.1 & 33.9 & المتوسط \\
\hline 184.5444 & 184.5444 & التباين \\
\hline \multirow[t]{5}{*}{10} & 10 & عدد الششاهدات \\
\hline & -1 & معامل بيرسون \\
\hline & 0 & Hypothesized Mean Difference \\
\hline & 9 & Df \\
\hline & -8.98539 & t Stat \\
\hline
\end{tabular}

وصف الجدول: من جدول التكرارات والنسب المئوية لاجابات عبارات تشير نتائج مقياس تحليل

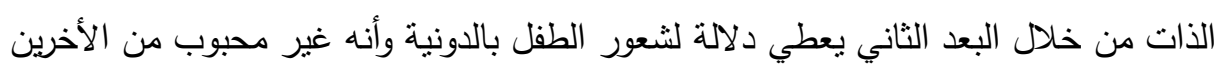

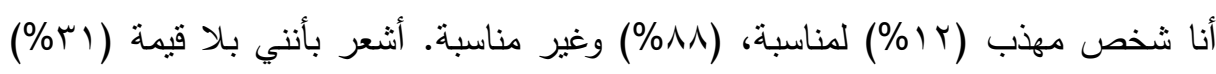

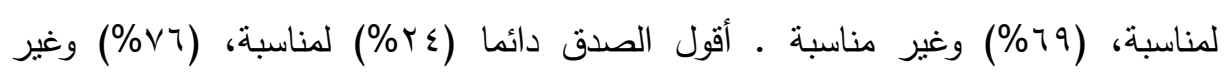

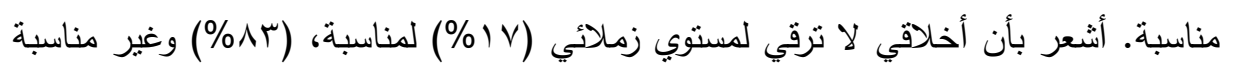

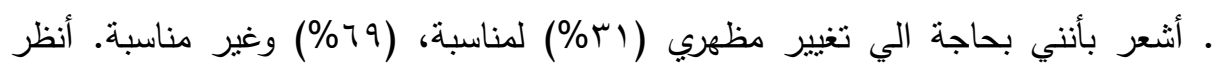

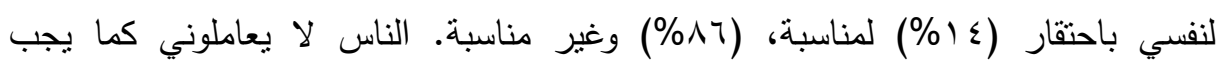

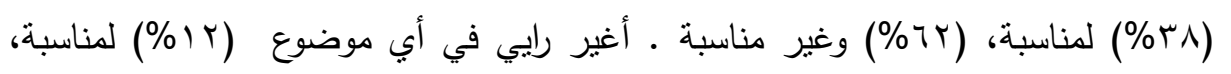

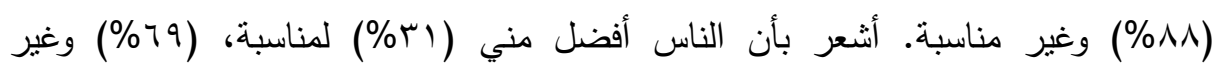

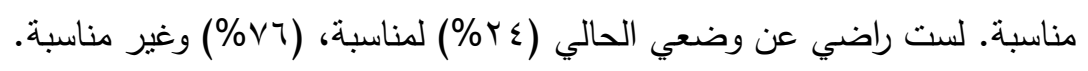

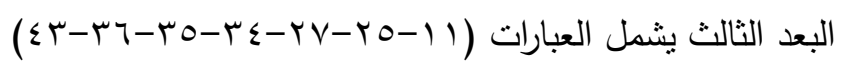
يعطي دلالة لشعور الطفل بأن لدية ميول عدوانية تجاه الأخرين 
جدول(r I): النسب المئوية للبعد الرابع الذي يعطي دلالة لشعور الطفل بأن لدية ميول عدوانية تجاه الأخرين

\begin{tabular}{|c|c|c|c|c|c|}
\hline$\%$ & غير مناسبة & $\%$ & مناسبة & العبارة & מ \\
\hline 82.07 & 119 & 1717.93 & $\overline{r T}$ & أصدقائى شخص غير محبوب بين & 11 \\
\hline 75.86 & 11. & 24.14 & ro & أقوم باعمال سيئة جدا & ro \\
\hline 68.97 & $\ldots$ & 31.03 & «o & أنا شخص فاشل & TV \\
\hline 68.97 & $\ldots$ & 31.03 & $\sum 0$ & أنا شخص سيء & $\Gamma \xi$ \\
\hline 72.41 & 1.0 & 27.59 & $\varepsilon$. & أتتصرف في بعض المواقف بغباء & ro \\
\hline 75.86 & 11. & 24.14 & ro & لا أَستطيع التأقلم مع الاخرين & ז \\
\hline 82.07 & 119 & 17.93 & rq & أنا شخص حاسد لزملائي & $\varepsilon r$ \\
\hline
\end{tabular}

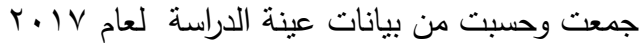

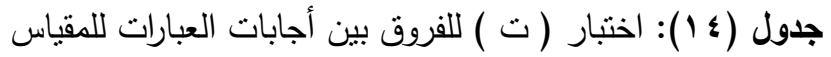

\begin{tabular}{|c|c|c|}
\hline غير مناسبة & مناسبة & المتغيرات \\
\hline 109 & 36 & المتوسط \\
\hline 63.33 & 63.33 & التباين \\
\hline \multirow[t]{5}{*}{7} & 7 & عدد المشاهدات \\
\hline & -1 & معامل بيرسون \\
\hline & 0 & Hypothesized Mean Difference \\
\hline & 6 & Df \\
\hline & -12.1346 & t Stat \\
\hline
\end{tabular}

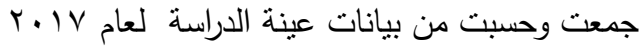
وصف الجدول: من بيانات جدول التكرارات والنسب المئوية لاجابات عبارات نتير نتائج

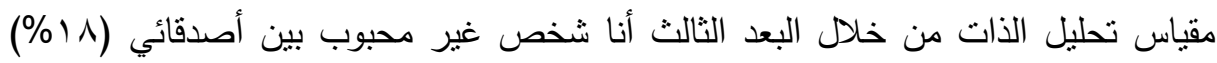

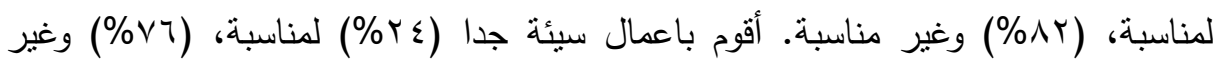

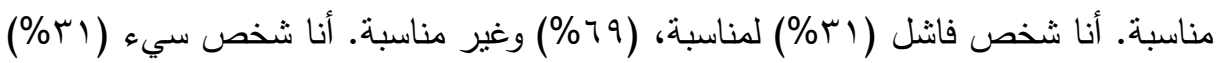

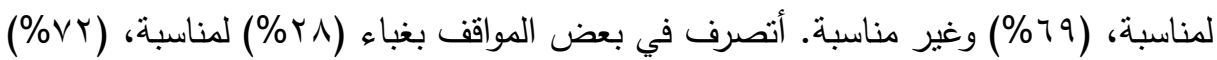

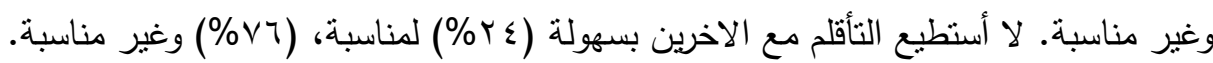
أنا شخص حاسد لزملائي (^\\%) لمناسبة، (Y^\%) وغير مناسبة.

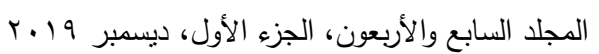




$$
\begin{aligned}
& \text { البعد الرابع يشمل العبارات (r-乏- } \\
& \text { يعطي دلالة لاتزان الطفل نفسيا وموضوعيتة مع الأخرين }
\end{aligned}
$$

جدول (0 1): النسب المئوية للبعد الرابع الذي يعطي دلالة لاتزان الطفل نفسيا وموضوعيته الاحتين

\begin{tabular}{|c|c|c|c|c|c|}
\hline$\%$ & مناسبة & $\%$ & مناسبة & العبارة & b \\
\hline 82.76 & 120 & 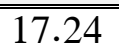 & 25 & أنا شخص مهذب & $\overline{\mathrm{T}}$ \\
\hline 79.31 & 115 & 20.69 & 30 & أنا شخص أمين & $\varepsilon$ \\
\hline 75.86 & 110 & 24.14 & 35 & أنا راضي عن نفسي & 10 \\
\hline 72.41 & 105 & 27.59 & 40 & الاخُشربن بالرضا عن علاقاني مع & 17 \\
\hline 79.31 & 115 & 20.69 & 30 & أنا راضي عن شكلي الحالي & IV \\
\hline 79.31 & 115 & 20.69 & 30 & أناس راضي عن أسلوبي في معاملة & T乏 \\
\hline 72.41 & 105 & 27.59 & 40 & بذلك عن غلطتي فورا عندما أحس & YA \\
\hline 79.31 & 115 & 20.69 & 30 & أتصرف في كل أموري بشكل صحيح & rq \\
\hline 81.38 & 118 & 18.62 & 27 & أققبل نقد الاخرين & $\xi$ \\
\hline 84.83 & 123 & 15.17 & 22 & أنا احب المكان الذي أعيش فيه & $\varepsilon \varepsilon$ \\
\hline
\end{tabular}

$$
\text { مع الأخرين }
$$

\begin{tabular}{|c|c|c|}
\hline غير مناسبة & مناسبة & المتغيرات \\
\hline 114.1 & 30.9 & المتوسط \\
\hline 34.99 & 34.99 & التباين \\
\hline \multirow[t]{5}{*}{10} & 10 & عدد المشاهدات \\
\hline & -1 & معامل بيرسون \\
\hline & 0 & Hypothesized Mean Difference \\
\hline & 9 & Df \\
\hline & -22.24 & t Stat \\
\hline
\end{tabular}

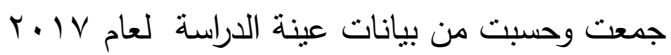

جدول (ד 1): اختبار ( ت ) للفروق بين إجابات العبارات للمقياس

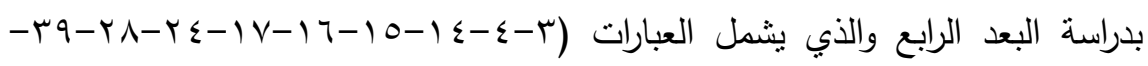

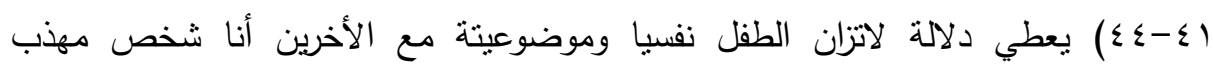

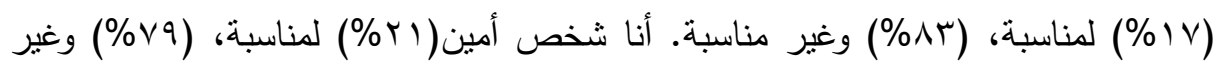


مناسبة. أنا راضي عن نفسي (\&Y\%) لمناسبة، (\%V7\%) وغير مناسبة ـ أشثعر بالرضا عن

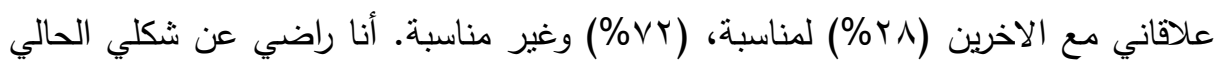

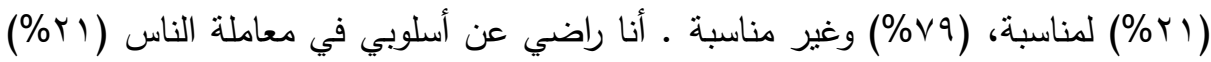

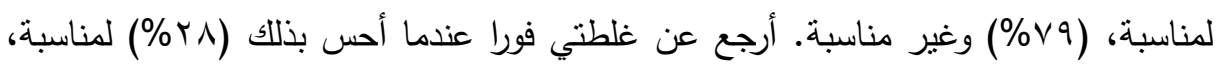
(\%VY)

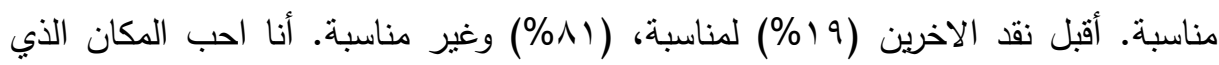

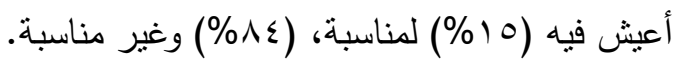

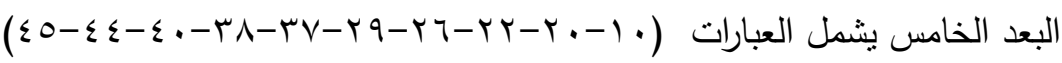
يعطي دلالة التقة بالنفس ورغبته في أن يكون منميزا عن الأخرين جدول (IV): البعد الخامس يعطي دلالة الثقة بالنفس ورغبته في أن يكون متميزا عن الأخرين

\begin{tabular}{|c|c|c|c|c|c|}
\hline$\%$ & مناسيبة & $\%$ & مناسبة & 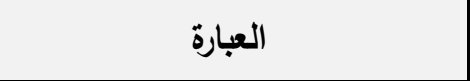 & م \\
\hline 75.86 & 110 & 24.14 & 35 & أحب أن أكون حسن المظهر & 1. \\
\hline 77.93 & 113 & 22.07 & 32 & أتمنى لو أكون أكثر جاذبية & $r$. \\
\hline 82.76 & 120 & 17.24 & 25 & أنشعر أننى الان على مايرام & KY \\
\hline 75.86 & 110 & 24.14 & 35 & أحاول أن أتكيف مع الاخرين & $r 7$ \\
\hline 72.41 & 105 & 27.59 & 40 & لدي رغبة أن أهتم بمظهري & rq \\
\hline 72.41 & 105 & 27.59 & $\varepsilon$. & يقدرها بانني لاي مواهب ولكن لاأحد & rv \\
\hline 65.52 & 90 & 34.48 & 50 & أَشعر باننى مراقب من كل الاخرين & $r \Lambda$ \\
\hline $71,9 V$ & 100 & 31.03 & 45 & أحاول الهروب من مشاكلى & $\varepsilon$. \\
\hline 82.76 & 120 & 17.24 & 25 & أنا احب المكان الذي أعيش فيه & $\varepsilon \varepsilon$ \\
\hline 86.21 & 125 & 13.79 & 20 & أخنا اتعاون مع زملائي من أجل فعل & ¿0 \\
\hline
\end{tabular}

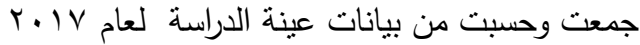


جدول (1 ا): اختبار ( ت ) للفروق بين أجابات العبارات للمقياس

\begin{tabular}{|c|c|c|}
\hline غير مناسبة & مناسبة & المتغيرات \\
\hline 110.3 & 34.7 & المتوسط \\
\hline 989.7 & 989.7 & التباين \\
\hline \multirow[t]{5}{*}{10} & 10 & عدد العبارات \\
\hline & -1 & معامل بيرسون \\
\hline & 0 & Hypothesized Mean Difference \\
\hline & 9 & Df \\
\hline & $r-12.6$ & t Stat \\
\hline
\end{tabular}

وصف الجدول: من بيانات جدول النكرارات والنسب المئوية لاجابات عبارات نتشير نتائج مقياس تحليل الذات من خلال البعد الخامس يعطي دلالة الثقة بالنفس ورغبته في أن يكون

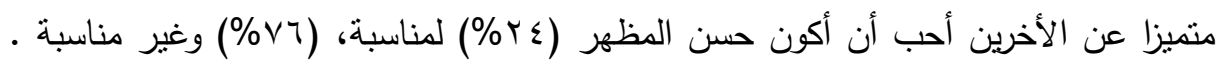

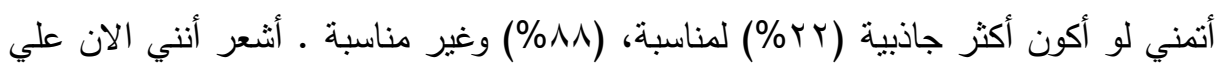

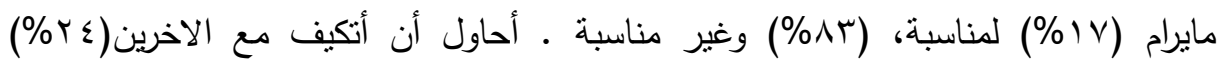

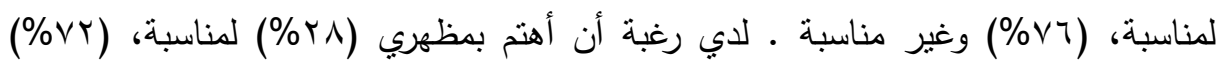

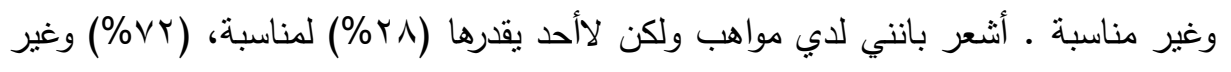

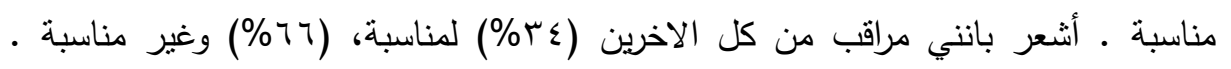

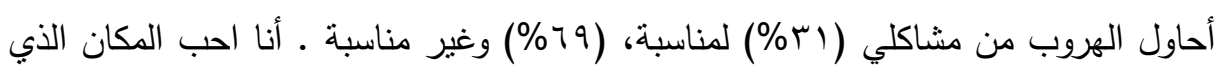

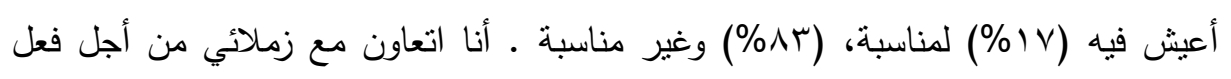

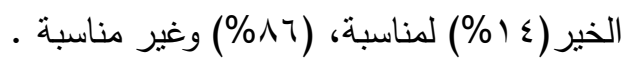
بدراسة نتائج الدراسة الحالية بهدف التعرف علي مدي الاتساق وعدم الاتساق مع الدراسات السابقة تبين النقاط التالية :اتفقت نتائج الدراسة من حيث الاتساق مع دراسة كلا من

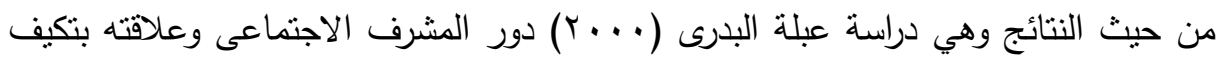

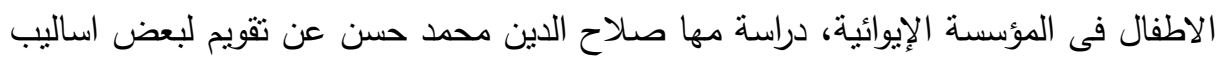

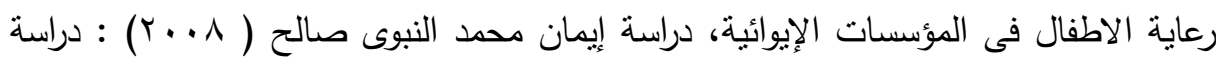

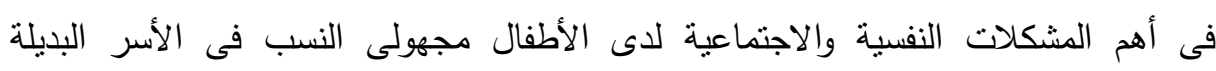

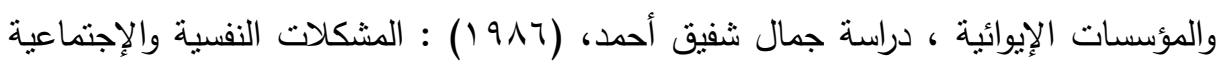

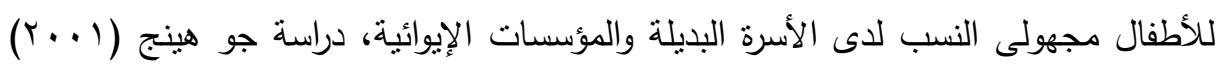
138

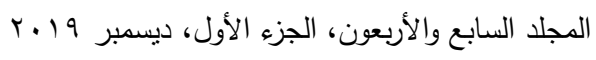


Haug - Chau

$$
\text { الإيوائية فى سن المدرسة }
$$

\section{توصيات الدراسة وتوصي الدراسة بالنقاط التالية :}

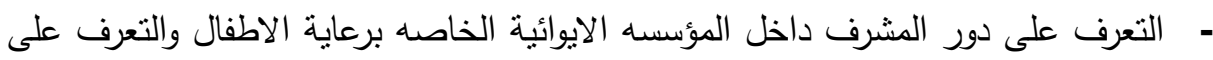
الهيكل التظظيمي داخل المؤسسه وكيف يمكن ان يؤثر على الطلل .

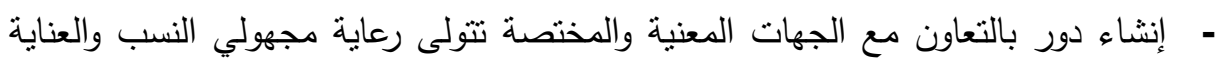
بهم وتقديم الرعاية الثشاملة لهم وعلى وجه الخصوص من حيث تأمين الخدمات المعيشية

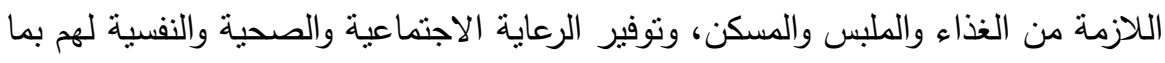
يتتاسب ومراحل أعمارهم المختلفة، وغرس القيم النبيلة وترسيخ المبادئ والأخلاق الإسلامية فيهم.

- إضافة إلى توفير فرص تعليم متكافئة في مراحل التعليم المختلفة في جميع المؤسسات

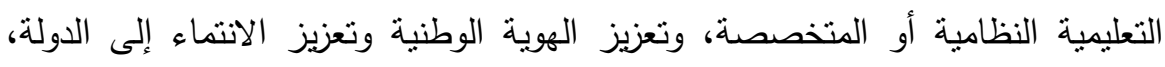

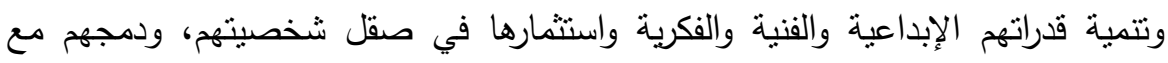
غيرهم من الأطفال في المراكز والأندية الرياضية والثقافية والمخيمات وتوفيه ولهير الأنشطة

$$
\text { المناسبة لهم. }
$$

\section{2all}

البواب، خليل، الموسوعه النفسية، طا، دار اليوسف للنشر ، لبنان ع . . ب ـ

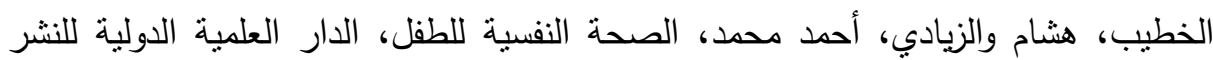

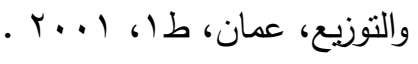

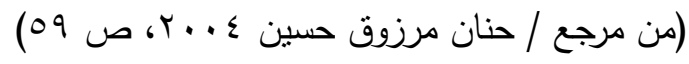

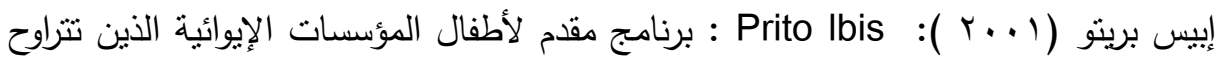

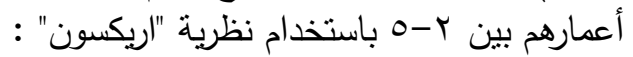

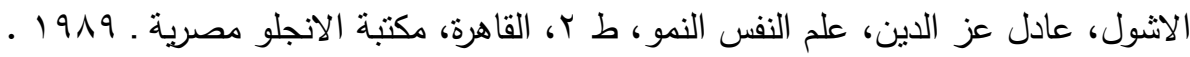

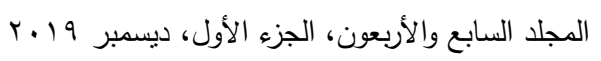




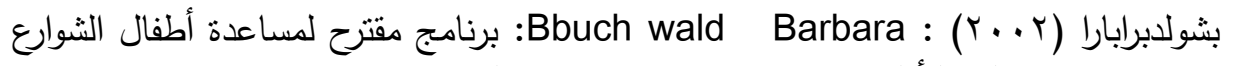

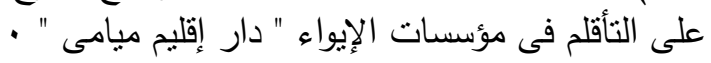

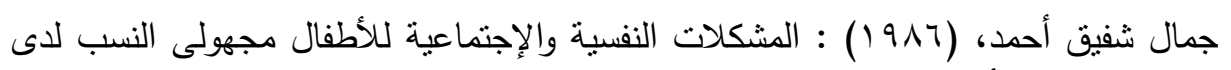
الأسر ة البديلة والمؤسسات الإيوائية:

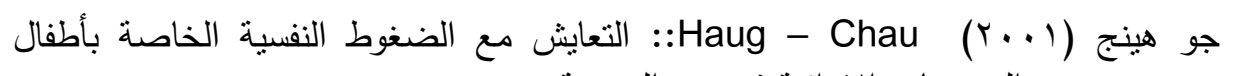
المؤسسات الإيوائية فى سن المدرسة التعائ

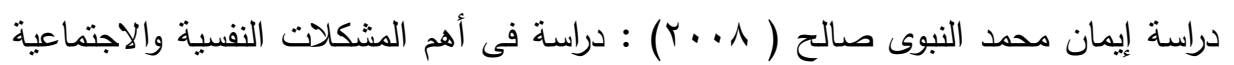

لدى الأطفال مجهولى النسب فى الأسر البديلة والمؤسسات الإيوائية :

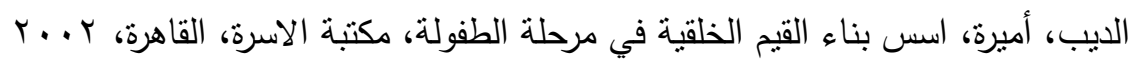

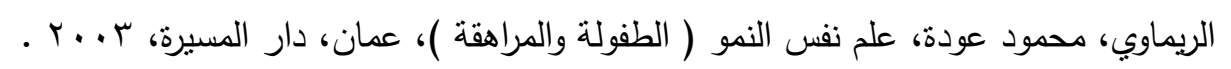

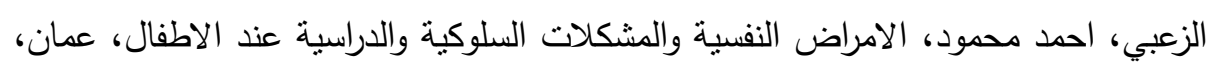

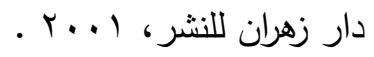

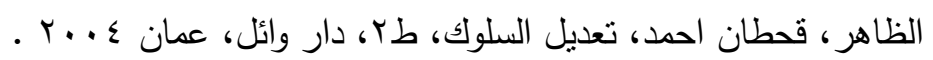

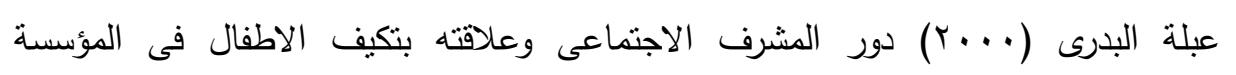
الإيوائية.

علاونه، شفيق فلاح، سيكولوجية النطور الانساني في الطفولة، عمان، ط ال، دار المسيرة،

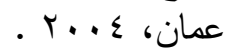

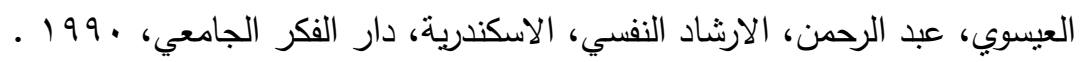

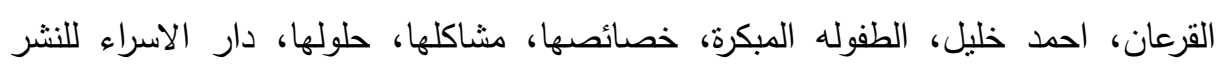

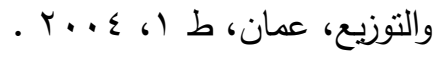

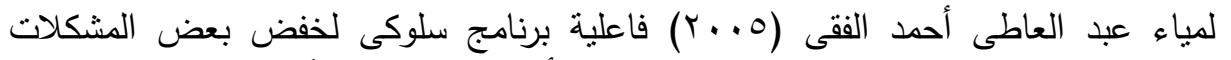

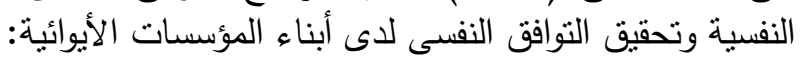

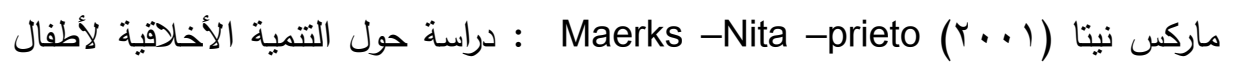
الثوارع الذين يعيشون فى مؤسسات الإيواء :

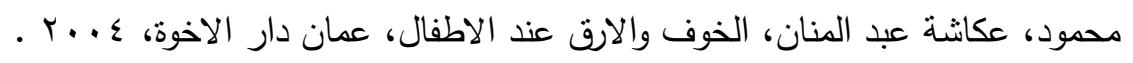

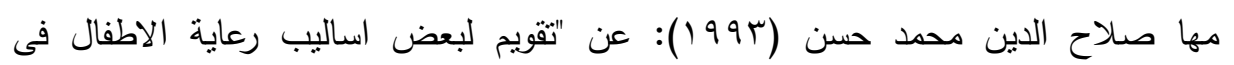
المؤسسات الإيوائية " الاين 
مجلة العلوم البيئية

معهد الدراسات والبحوث البيئة - جامعة عين شمس لئس

\title{
SELF CONCEPT AND AGGESSIONTO THE \\ CHILDREN OF UNKNOWN KINSHIP.- SOCIAL \\ STUDY ON CIVIL ASSOCIATIONS IN CAIRO \\ GOVERNORATE AND MINUTIA
}

\author{
Aya I. Ibrahim ${ }^{(1)}$; Rizke S. Ibrahim ${ }^{(2)}$ Ahmed Y. Abdelhamid ${ }^{(3)}$
}

1) Post grad. Institute of Environmental studies and Research, Ain Shams University 2) Faculty of Arts, Ain Shams University 3) Faculty of Arts, Suez Canal University

\begin{abstract}
The study aimed to identify the most important psychological and social problems of children of unknown origin within the rural and urban recreational institutions. And the development of a therapeutic program for the social and psychological problems of children of unknown origin in the rural and urban recreational institutions. And study the concept of self in children of unknown descent in the countryside and urban. The problem of the study stems from the exposure of children of unknown origin to the psychological and social problems suffered by children in residential establishments in rural and urban areas and an attempt to find out how to deal with them. This study is an analytical descriptive study. The researchers used the scientific method through the study sample and its characteristics. It included (145 children of unknown origin in the accommodation establishments in Cairo and Menoufia governorate), which were taken in the random sample method distributed in (74 individuals in urban environment, 71 individuals in rural environment) Researcher for data collection, preliminary questionnaire form, self-analysis scale (researcher preparation) using previous studies and research.
\end{abstract}

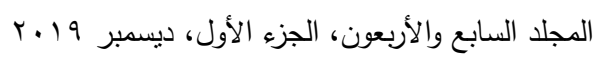


The most important results of the study are the identification of the role of the supervisor within the child care institution and the organizational structure within the organization, by establishing a role in cooperation with the competent and competent authorities to take care of the unknown persons and care for them and provide them with comprehensive care, Clothing and housing, and providing social, health and psychological care to them in proportion to the different stages of their ages, and instilling noble values and the consolidation of Islamic principles and ethics in addition to providing equal education opportunities in different stages of education in c Aa educational institutions, formal or specialized, and the strengthening of national identity and the promotion of belonging to the state, and the development of creative, artistic and intellectual abilities and invest in refining their personality, and integrating them with other children in the centers, sports and cultural clubs and camps and to provide appropriate activities for them. 